\title{
Potential for codends with shortened lastridge ropes to replace mandated selection devices in demersal trawl fisheries
}

\author{
Manu Sistiaga, Jesse Brinkhof, Bent Herrmann, Roger B. Larsen, Eduardo Grimaldo, Kristine Cerbule, \\ Ilmar Brinkhof, and Terje Jørgensen
}

\begin{abstract}
In many trawl fisheries, codend size selectivity is supplemented by adding selection devices to the gear. In the Barents Sea gadoid fishery, combining diamond mesh codends with sorting grids is compulsory. However, the use of grids increases the costs and complexity of the gear, causing discontent among fishermen and prompting researchers to seek alternative solutions. Lastridge ropes are ropes attached to the selvedges of the codend. In this study, we tested the effect of shortening the lastridge ropes of two diamond mesh codends with different mesh sizes on the size selectivity of cod (Gadus morhua), haddock (Melanogramus aeglefinnus), and redfish (Sebastes spp.). Shortening the lastridge ropes by $15 \%$ increased the mesh opening during the fishing process, which significantly improved the size-selective properties of the codends. Further, the L50 values were always higher for the codends in the short lastridge configuration. Therefore, codends with shortened lastridge ropes may be a simpler alternative to sorting grids in this fishery, and they may be applicable to many other fisheries in which additional selection devices are used.

Résumé : Dans de nombreuses pêches au chalut, la sélectivité selon la taille des culs de chalut est rehaussée en ajoutant aux engins des dispositifs de sélection d'appoint. Dans la pêche aux gadidés de la mer de Barents, il est obligatoire de combiner des grilles séparatrices aux culs de chalut à maille en losange. L'utilisation de grilles accroît les coûts et la complexité des engins, ce qui cause du mécontentement chez les pêcheurs et incite les chercheurs à explorer d'autres solutions. Les ralingues sont des cordes attachées aux lisières du cul de chalut. Nous avons vérifié l'effet du raccourcissement des ralingues de deux culs de chalut à maille en losange à mailles de différentes dimensions sur la sélectivité de la taille des morues (Gadus morhua), des aiglefins (Melanogramus aeglefinnus) et des sébastes (Sebastes spp.). Un raccourcissement de $15 \%$ des ralingues accroît l'ouverture des mailles durant le processus de pêche, ce qui améliore significativement les propriétés de sélection selon la taille des culs de chalut. En outre, les valeurs L50 sont toujours plus grandes pour les configurations de cul de chalut intégrant des ralingues raccourcies. Les culs de chalut dotés de ralingues raccourcies pourraient donc constituer une solution de rechange plus simple aux grilles séparatrices dans cette pêche et pourraient éventuellement être employés dans de nombreuses autres pêches dans lesquelles des dispositifs de sélection d'appoint sont utilisés. [Traduit par la Rédaction]
\end{abstract}

\section{Introduction}

Diamond mesh codends are the most widespread and simplest size-selection device used in demersal trawls, and in some fisheries, size selectivity relies solely on the selective properties of this type of codend (Cheng et al. 2019). However, diamond mesh codends can pose challenges and yield varying or unsatisfactory results (Robertson and Stewart 1988; Sala et al. 2008; Wienbeck 2011). For example, as the catch in the codend builds up during towing and haul-back, tension increases and the longitudinal forces in the mesh bars close the codend meshes, affecting selectivity (Robertson and Stewart 1988; Herrmann 2005a, 2005b; Herrmann and O’Neill 2005; Herrmann et al. 2007; O’Neill and Herrmann
2007). The meshes at these stages will generally maintain their diamond shape and fish will most likely not be able to deform the netting and escape. However, when the codend is at the surface with low or no tension, the meshes can be both wide open (up to 90 degrees) and slack, which could give fish trying to escape the chance to distort the mesh shape to fit their cross-sectional shape and escape through it (Herrmann et al. 2016).

An obvious management approach to solving trawl selectivity issues would be to modify the codend. However, in many fisheries the approach adopted has been to insert additional devices into the gear, such as square mesh panels (Graham et al. 2003; Herrmann et al. 2015; Cuende et al. 2020) or sorting grids (Sistiaga et al. 2008; Brinkhof et al. 2020), to supplement codend size

Received 23 June 2021. Accepted 25 October 2021.

M. Sistiaga.* Institute of Marine Research, Postbox 1870 Nordnes, N-5817 Bergen, Norway; Norwegian University of Science and Technology, Otto Nielsens veg 10, N-7491 Trondheim, Norway.

J. Brinkhof,* R.B. Larsen, and I. Brinkhof. The Arctic University of Norway, UiT, Breivika, N-9037 Tromsø, Norway.

B. Herrmann.* The Arctic University of Norway, UiT, Breivika, N-9037 Tromsø, Norway; SINTEF Ocean, Brattørkaia 17C, N-7010 Trondheim, Norway; DTU Aqua, Technical University of Denmark, Willemoesvej 2, DK-9850 Hirtshals, Denmark.

E. Grimaldo and K. Cerbule. The Arctic University of Norway, UiT, Breivika, N-9037 Tromsø, Norway; SINTEF Ocean, Brattørkaia 17C, N-7010 Trondheim, Norway.

T. Jørgensen. Institute of Marine Research, Postbox 1870 Nordnes, N-5817 Bergen, Norway.

Corresponding author: Manu Sistiaga (email: manu.sistiaga@hi.no).

${ }^{*}$ Equal authorship.

() 2021 The Author(s). This work is licensed under a Creative Commons Attribution 4.0 International License (CC BY 4.0), which permits unrestricted use, distribution, and reproduction in any medium, provided the original author(s) and source are credited. 
selectivity. One such fishery is the Barents Sea gadoid trawl fishery, which is one of the most important demersal fisheries in the world (Bergstad et al. 1987; Olsen et al. 2010). In this fishery, the diamond mesh codend is supplemented by a rigid sorting grid, which became compulsory in 1997 due to unsatisfactory size selection of the diamond mesh codend alone (Larsen and Isaksen 1993). The current compulsory size-selection gear is a dual system composed of a sorting grid with a minimum bar spacing of $55 \mathrm{~mm}$ and a subsequent diamond mesh codend with a minimum mesh size of $130 \mathrm{~mm}$ (Norwegian Directorate of Fisheries 2017). Fishermen can choose among three different sorting grid systems (Sort-X, Sort-V, and Flexigrid) that have been developed over time since the first trials were conducted in the early 1990s (Larsen and Isaksen 1993; Grimaldo et al. 2016).

The fishing industry would like to remove the mandatory use of grids from the regulations because they are expensive, heavy, and can substantially influence water flow in the extension piece and codend (Grimaldo et al. 2016). Reduced water flow in the aft part of the trawl can lead to fish accumulation, which can result in section breakage (Sistiaga et al. 2016) and failure of catch limiters and catch sensors (Grimaldo et al. 2014). In addition, the three grid systems may not be equally efficient, and their performance can vary substantially depending on factors such as catch densities and whether the section is constructed of two or four panels (Sistiaga et al. 2016; Brinkhof et al. 2020).

The mandatory use of selection grids in the Barents Sea demersal trawl fishery has been questioned since it was made compulsory in 1997 (Jørgensen et al. 2006). Simple codend modifications or additional devices such as exit windows or square mesh sections have been tested as potential alternatives (Jørgensen et al. 2006; Grimaldo et al. 2008, 2018). Although some of the sorting devices have shown selection properties similar to those of the sorting grids, issues related to how to mount the devices and how to objectively monitor and control their use have prevented their implementation. Another approach that does not require additional devices and is relatively simple to implement and control is to attach short lastridge ropes in the codend. Lastridge ropes are ropes attached to the selvedges of the codend, and they are normally slightly shorter than the codend netting (e.g., typically $0 \%-5 \%$ in the Barents Sea). This type of rope is normally used in fisheries like the Barents Sea demersal fishery where the catches can be large (e.g., $>10$ tonnes). When the catch builds up, most of the load is carried by these ropes rather than by the netting in the codend. By shortening the lastridge ropes further, they would bear the load of the catch to a greater extent than in a typical codend. Consequently, the tension in the codend netting would remain low as the catch accumulates, resulting in more open meshes during fishing, which should improve the selective properties of the codend (Isaksen and Valdemarsen 1990; Lök et al. 1997; Ingolfsson and Brinkhof 2020).

Cod (Gadus morhua) and haddock (Melanogrammus aeglefinus) are the main target species in the Barents Sea demersal trawl fishery, and redfish (Sebastes spp.) are among the main bycatch species. Large cod and haddock often acquire a higher price per kilogram than smaller individuals, and fishermen generally aim to maximize the revenue from their limited quotas. Therefore, fishermen in this area often are interested in only catching cod and haddock well above (approximately $5 \mathrm{~cm}$ ) the minimum legal size (MLS), which is $44 \mathrm{~cm}$ for cod and $40 \mathrm{~cm}$ for haddock. The MLS for redfish is $32 \mathrm{~cm}$. These three fish have substantial morphological (Sistiaga et al. 2011; Herrmann et al. 2012) and behavioral differences (Engås and Godø 1989; Larsen et al. 2016). Thus, the effects of gear modifications on size-selection properties and catch patterns vary among them.

Although earlier studies have documented the performance of codends with shortened lastridge ropes compared to other gear (Lök et al. 1997; Ingolfsson and Brinkhof 2020), research documenting the potential gains of applying shortened lastridge ropes in the codend is limited (Isaksen and Valdemarsen 1990). Thus, the objectives of this study were to investigate the effect of shortening the lastridge ropes on codends with different mesh sizes and to evaluate how the changes affect the selectivity and catch patterns of cod, haddock, and redfish in the Barents Sea demersal trawl fishery. Considering the MLS and exploitation pattern desired by fishermen for the different species involved, we also investigated whether codends with shortened lastridge ropes could realistically replace the grid system required in the fishery today. Specifically, the research was designed to answer the following research questions:

1. Do shortened lastridge ropes modify the selection properties of diamond mesh codends for cod, haddock, and redfish? If so, then to what extent?

2. Is it possible to explain the selectivity results obtained for cod, haddock, and redfish by their species-specific characteristics and potential changes in the codend meshes generated by shortening the lastridge ropes?

3. Can shortened lastridge codends provide the desired catch patterns for cod, haddock, and redfish so that they could replace the grid system required in the Barents Sea demersal trawl fishery?

\section{Materials and methods}

\section{Study area, experimental design, and data collection}

Experimental fishing was conducted onboard the research vessel Helmer Hanssen (63.9 m long, $4080 \mathrm{HP}(3000 \mathrm{~kW})$ ) from 8 to 16 January 2021 in the southern part of the Barents Sea $\left(71^{\circ}\right.$ $22^{\prime} 65^{\prime \prime} \mathrm{N}-72^{\circ} 08^{\prime} 30^{\prime \prime} \mathrm{N}, 25^{\circ} 48^{\prime} 92^{\prime \prime} \mathrm{E}-30^{\circ} 13^{\prime} 44^{\prime \prime} \mathrm{E}$ ). The experimental fishing was conducted using an Alfredo 5 twin-body trawl (trousertrawl; Grimaldo et al. 2007) combined with a set of Injector Scorpion trawl doors, each weighing $3100 \mathrm{~kg}$ and with an area of $8 \mathrm{~m}^{2}$. The trawl doors were connected to the sweeps with $3 \mathrm{~m}$ long backstraps followed by $7 \mathrm{~m}$ long connector wires. The sweeps were $2 \mathrm{~m} \times 30 \mathrm{~m}$ long and divided by a $\emptyset 53 \mathrm{~cm}$ steel bobbin in the middle to protect them from excessive abrasion. The sweeps were connected to a $48 \mathrm{~m}$ long ground gear, which consisted of a $14 \mathrm{~m}$ long chain $(\emptyset 19 \mathrm{~mm})$ with four equally spaced bobbins $(\emptyset 53 \mathrm{~cm})$ on each side with a rock-hopper gear in the middle. The rock-hopper gear was $21 \mathrm{~m}$ long and equipped with $\emptyset 53 \mathrm{~cm}$ discs. The headline in the trawl was $38 \mathrm{~m}$ long, and it was equipped with 170 floats (8 inch; 1 inch $=2.5 \mathrm{~cm}$ ). The trawl net itself was a modified $155 \mathrm{~mm}$, twopanel Alfredo 5 twin-body trawl. A vertical panel (\# $80 \mathrm{~mm}$ ) was inserted in the front part of the trawl body to divide it into two equal sections. At the end of the vertical net, the trawl body was split into two equal $23.3 \mathrm{~m}$ long tapered funnels (Fig. 1a). Each funnel was followed by a $14.1 \mathrm{~m}$ long extension piece, which took the place of the grid section that is compulsory in the commercial fishery. The codends were mounted directly onto the extension pieces and consisted of two panels made of single braided polyethylene hotmelt twine $(\varnothing 8 \mathrm{~mm})$. Each codend was $12 \mathrm{~m}$ long and 60 free meshes in circumference. The two codends had different mesh sizes: $128.23 \pm 3.97 \mathrm{~mm}$ and $137.08 \pm 2.28 \mathrm{~mm}$. These two mesh sizes represent the minimum mesh size used by the fleet in the fishery $(130 \mathrm{~mm})$ and a codend with approximately $1 \mathrm{~cm}$ bigger meshes. The selvedges of the codends were strengthened with $\emptyset 32 \mathrm{~mm}$ (Polyethylene, Danline) thick lastridge ropes. During the first part of the experimental period, the two codends were tested with a regular lastridge rope configuration (no shortening), whereas in the second part of the experimental period the lastridge ropes in the last $6 \mathrm{~m}$ of both codends were shortened by $15 \%$.

The entire length of the codends was covered with smallmeshed covers that caught fish escapees. To ensure that the covers stayed clear of the codend netting, the front part of each of the covers was equipped with six floats, three kites, and a $12 \mathrm{~kg}$ 
Fig. 1. Illustration showing the twin-body trawl $(a)$ and the configuration of the covers (CC) over the codends (C) (b). [Colour online.]

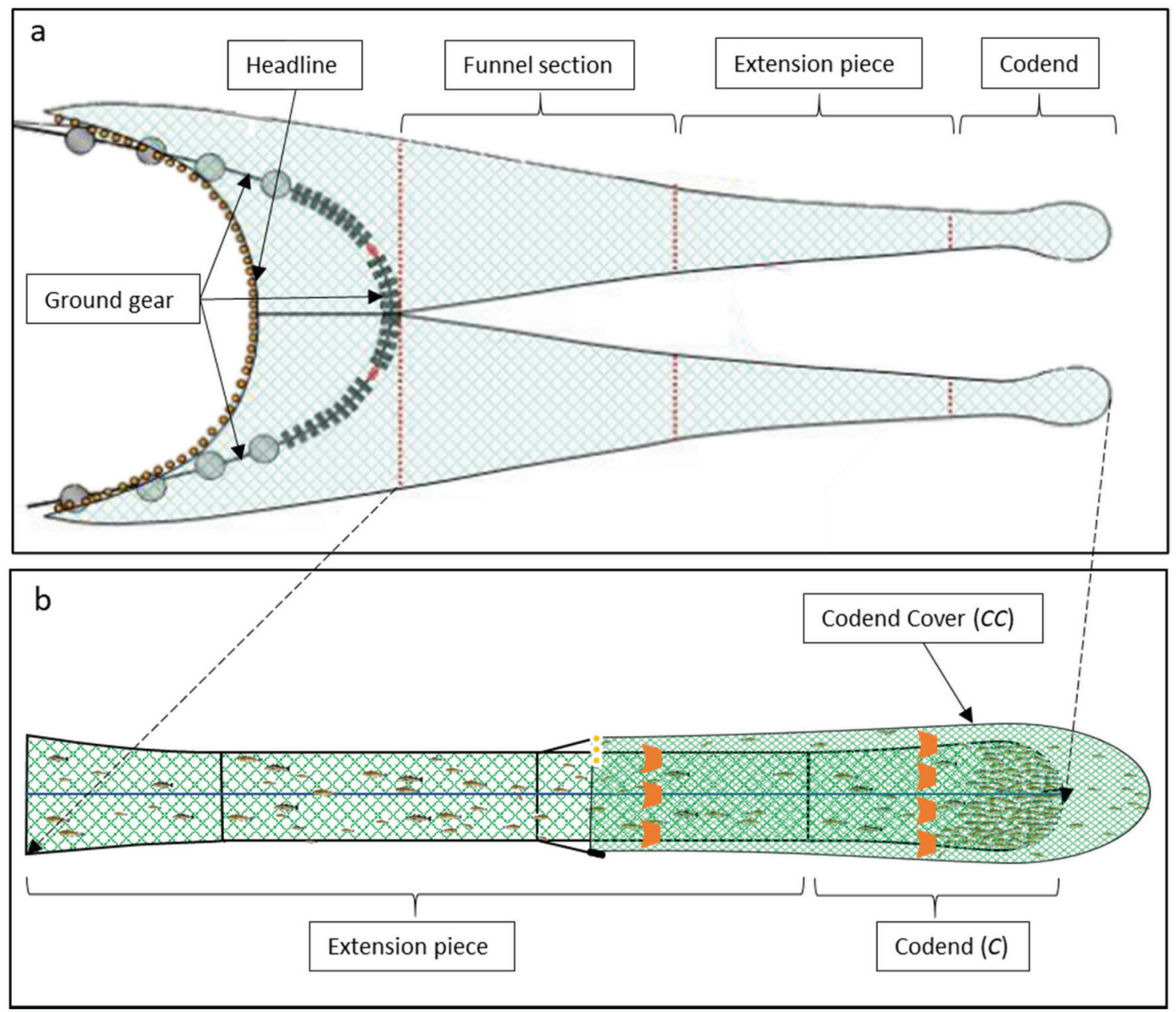

piece of chain on the top, side, and bottom part of the codend, respectively (Fig. 1b). Further, each of the covers had 12 kites attached to the cover around the bulk of the catch in the codend. The covers had a nominal mesh size of $50 \mathrm{~mm}$ and were strengthened with an outer layer of large-meshed netting in the aft part.

The performance of the trawl was monitored continuously with a set of trawl door sensors, a trawl height sensor, and a catch volume sensor. During the trials, the catch from each compartment was kept in separate holding bins. The length of all cod, haddock, and redfish above $20 \mathrm{~cm}$ was measured to the nearest centimetre rounded down.

Modeling and estimation of the size selection in the codends

To identify potential selectivity differences between the different codends tested, it was first necessary to estimate the size-selection properties of each of the different codends tested individually. The data for each species were analyzed separately using the method described here. The experimental design (Fig. 1) applied to test the codends enabled us to analyze the catch data as binominal data. The numbers of individuals per length class, retained either by the codend cover or by the codend itself, were used to estimate the size selection in the codend (i.e., length-dependent retention probability). The size selectivity between hauls for the same codend is expected to vary (Fryer 1991). However, we were interested in the size selection averaged over hauls because it would provide information about the average consequences for the size-selection process when using the codend in the fishery. We tested different parametric models of the form $r_{\text {codend }}\left(l, \boldsymbol{v}_{\text {codend }}\right)$ for the codend size selection, where $\boldsymbol{v}_{\text {codend }}$ is a vector consisting of the parameters in the model. The purpose of the analysis was to estimate the values of the parameters in $v_{\text {codend }}$ that maximized the likelihood for the experimental data (averaged over hauls) to be obtained. For this purpose, the following expression was minimized, which corresponds to maximizing the likelihood for obtaining the observed experimental data:

$$
\begin{aligned}
-\sum_{j=1}^{m} \sum_{l}\left\{\mathrm{nC}_{l j} \times \ln \left[r_{\text {codend }}\left(l, v_{\text {codend }}\right)\right]\right. & +\mathrm{nCC}_{l j} \\
& \left.\times \ln \left[1.0-r_{\text {codend }}\left(l, \boldsymbol{v}_{\text {codend }}\right)\right]\right\}
\end{aligned}
$$

where $\mathrm{nC}_{l j}$ and $\mathrm{nCC}_{l j}$ are the numbers of fish in the codend and codend cover for length class $l$ in haul $j$, respectively.

The outer summation in eq. 1 comprises the hauls $j$ (from 1 to $m$ ) conducted with the specific codend, and the inner summation is over the length classes $l$ in the data.

Four different models were chosen as basic candidates to describe $r_{\text {codend }}\left(l, \boldsymbol{v}_{\text {codend }}\right)$ for each codend and species individually: Logit, Probit, Gompertz, and Richard. The first three models are fully described by the selection parameters L50 (length of fish with $50 \%$ probability of being retained) and SR (difference in length between fish with $75 \%$ and $25 \%$ probability of being retained, respectively), whereas the Richard model requires an additional parameter $(d)$ that describes the asymmetry of the curve. The formulas for the four selection models and additional information can be found in Lomeli (2019). 
Evaluating the ability of a model to describe the data sufficiently well was based on estimating the corresponding $p$ value, which expresses the likelihood of obtaining at least as big a discrepancy between the fitted model and the observed experimental data by coincidence. Therefore, for the fitted model to be a candidate to model the sizeselection data, this $p$ value should not be $<0.05$ (Wileman et al. 1996). In case of a poor fit statistic $(p<0.05)$, the residuals were inspected to determine whether the poor result was due to structural problems when modeling the experimental data with the different selection curves or if it was due to overdispersion in the data (Wileman et al. 1996). The best model among the four considered was selected by comparing their Akaike information criterion (AIC) values. The model with the lowest AIC value was selected (Akaike 1974).

Once the specific size-selection model was identified for each species and codend configuration, bootstrapping was applied to estimate the confidence limits for the average size selection. We used the software tool SELNET (Herrmann et al. 2012) for the sizeselection analysis, and the double bootstrap method was implemented in the tool to obtain the confidence limits for the sizeselection curve and the corresponding parameters. This bootstrapping approach is identical to the one described in Millar (1993) and takes into consideration both within-haul and between-haul variation. The hauls for each codend configuration were treated as a group of hauls. To account for between-haul variation, an outer bootstrap resample with replacement from the group of hauls was included in the procedure. Within each resampled haul, the data for each length class were bootstrapped in an inner bootstrap with replacement to account for within-haul variation. For each species analyzed, 1000 bootstrap repetitions were conducted. Each bootstrap run resulted in a set of data that was pooled and then analyzed using the identified selection model. Thus, each bootstrap run resulted in an average selection curve. The Efron percentile $95 \%$ confidence limits for the average selection curve were obtained based on the same 1000 bootstrap repetitions (Efron 1982; Herrmann et al. 2012).

\section{Estimation of difference in size selectivity between codends}

The analysis presented in this subsection was linked to research question 1, which aimed at discerning if, and to what extent, shortened lastridge ropes modify the selection properties of diamond mesh codends.

The difference in size selectivity $\Delta r(l)$ between two codends $x$ and $y$ was estimated by

$$
\Delta r(l)=r_{y}(l)-r_{x}(l)
$$

where $x$ and $y$ represent the different codends, respectively. The 95\% confidence intervals (CIs) for $\Delta r(l)$ were obtained based on the two bootstrap population results for $r_{x}(l)$ and $r_{y}(l)$, respectively. As they were obtained independently of each other, a new bootstrap population of results for $\Delta r(l)$ was created using the procedure described in Larsen et al. (2018):

$$
\Delta r(l)_{i}=r_{y}(l)_{i}-r_{x}(l)_{i} \quad i \in[1 \ldots 1000]
$$

Finally, based on the bootstrap population, Efron 95\% percentile confidence limits were obtained for $\Delta r(l)$ as described above.

\section{Understanding codend size selection based on fish morphology and mesh geometry}

The objective of the analysis in this subsection was to answer research question 2 in the study; that is, investigate if it is possible to explain the selectivity results obtained for cod, haddock, and redfish by their morphological characteristics and the potential changes in the codend meshes generated by shortening the lastridge ropes.

Herein, we applied the FISHSELECT methodology, which is a framework of methods, tools, and software developed to determine if a fish can penetrate a certain mesh shape and size in fishing gear
(Herrmann et al. 2009), to estimate the size-selective potential for the diamond mesh codends used during the experimental fishing. Application of FISHSELECT to simulate size selectivity through codend meshes for a species requires (i) a morphological model describing the cross-sections of importance for size selection of the species and (ii) a model describing how and to what extent the fish cross-sections can be squeezed when trying to pass through a mesh. The FISHSELECT models necessary to study cod, haddock, and redfish size selectivity in diamond mesh codends for the Barents Sea demersal trawl fishery were already available from studies conducted by Sistiaga et al. (2011) and Herrmann et al. (2012). Based on these FISHSELECT models, we simulated the size selection in stiff diamond meshes (mesh shape cannot be deformed by fish trying to escape through it) with a mesh size identical to the two codends applied in the experimental fishing. Mesh opening angles between 10 and 90 degrees, in 10-degree increments, were tested to establish the potential size selection in the codend and its dependency on the mesh opening angle. In addition, we simulated the potential size selection for slack meshes (meshes can potentially be fully deformed by the effort of the fish while trying to escape) of the same mesh size. For each simulated size-selection data set obtained in this way, we fitted a logit selection model to obtain a size-selection curve. It is likely that fish will have multiple chances to attempt to escape, especially in the catch accumulation zone (Herrmann 2005a). If unsuccessful in a prior attempt, it is likely that decisive attempts will not be represented by the average mesh size but instead by meshes biased to some extent towards the maximum mesh size available in the codend. To account for this scenario in the simulations, we considered mean mesh sizes of 128 and $137 \mathrm{~mm}$ as well as mesh size + 2 times the standard deviations as an estimate for maximum mesh size for each of the codends (i.e., 134 and $142 \mathrm{~mm}$, respectively).

We also investigated whether the experimental size-selection data for cod, haddock, and redfish obtained for the different codends in the sea trials could be understood based on the FISHSELECT simulations. Therefore, we evaluated whether the experimental sizeselection curves based on the data collected during the sea trials could be replicated by simulating scenarios assuming different combinations of mesh states (i.e., mesh sizes and opening angles). We considered stiff diamond meshes for both the mean mesh sizes and the mean mesh sizes +2 times the standard deviation for opening angles between 10 and 90 degrees. We also considered slack meshes for all four mesh sizes. We then identified the combination of varying mesh openness and state that was best able to reproduce the experimental size-selection curves obtained during the experimental fishing for each species for each codend separately.

To conduct this analysis, we used the selection curves, with CIs and retention lengths, obtained from the analysis of the sea trial data and the simulated retention data for different mesh openness and different mesh states from FISHSELECT. We estimated the contributions needed from the different retention data to obtain combined selection curves that best fitted the experimentally obtained data. This procedure is identical to the one applied by Herrmann et al. $(2013,2016)$ and Cuende et al. $(2020)$, who provide detailed information on the technical aspects of the method.

\section{Exploitation pattern indicators for the codends}

To investigate how the different codend configurations affected the capture pattern for each species separately and address research question 3, we estimated the value of three exploitation pattern indicators, $\mathrm{nP}^{-}, \mathrm{nP}^{+}$, and $\mathrm{nDiscard}$ (discard ratio). These indicators are often used in fishing gear size selectivity studies to supplement assessment solely based on selectivity curves (Santos et al. 2016; Sala et al. 2017; Cheng et al. 2019; Kalogirou et al. 2019; Melli et al. 2020). To estimate these exploitation pattern indicators, we first applied the predicted sizeselection curves for each codend to the population of each species entering the fishing gear, which was estimated from the population entering the gear summed over all codends during the experimental fishing. The population size structure $\mathrm{nPop}_{l}$ for each individual 
species was obtained based on the data for all hauls from all codend designs by summing catches in the codend and cover. Uncertainties in populations were obtained by double bootstrapping following the approach described in Melli et al. (2020). We then estimated the percentage of individuals retained for individuals below $\left(\mathrm{nP}^{-}\right)$and above $\left(\mathrm{nP}^{+}\right)$a specified MLS, respectively, for each codend. We also estimated nDiscard, which is a measure of the number of undersized fish relative to the number of fish in the haul. For cod and haddock, we estimated the indicators for the current MLS ( 44 and $40 \mathrm{~cm}$, respectively) and for an MLS of $50 \mathrm{~cm}$ for cod and $45 \mathrm{~cm}$ for haddock, which represents the scenario in which fishermen are interested in catching fish only well above the MLS. Ideally, $\mathrm{nP}^{-}$and $\mathrm{nDiscard}$ should be low (close to 0), while $\mathrm{nP}^{+}$should be high (close to 100). The indicators were estimated for the different codends by

$$
\begin{aligned}
& \mathrm{nP}^{-}=100 \times \frac{\sum_{l<\mathrm{MLS}}\left[r_{\text {codend }}\left(l, \boldsymbol{v}_{\text {codend }}\right) \times \mathrm{nPop}_{l}\right]}{\sum_{l<\mathrm{MLS}}\left(\mathrm{nPop}_{l}\right)} \\
& \mathrm{nP}^{+}=100 \times \frac{\sum_{l>\mathrm{MLS}}\left[r_{\text {codend }}\left(l, \boldsymbol{v}_{\text {codend }}\right) \times \mathrm{nPop}_{l}\right]}{\sum_{l>\mathrm{MLS}}\left(\mathrm{nPop}_{l}\right)} \\
& \mathrm{nDiscard}=100 \times \frac{\sum_{l<\mathrm{MLS}}\left[r_{\text {codend }}\left(l, \boldsymbol{v}_{\text {codend }}\right) \times \mathrm{nPop}_{l}\right]}{\sum_{l}\left[r_{\text {codend }}\left(l, \boldsymbol{v}_{\text {codend }}\right) \times \mathrm{nPop}_{l}\right]}
\end{aligned}
$$

All indicators $\left(\mathrm{nP}^{-}, \mathrm{nP}^{+}\right.$, and $\left.\mathrm{nDiscard}\right)$ were estimated with uncertainties for each codend using the bootstrap set for $r_{\text {codend }}$ $\left(l, v_{\text {codend }}\right)$ and $\mathrm{nPop}_{l}$. Specifically, based on Herrmann et al. (2018), the bootstrap set for estimating indicator values was obtained based on each bootstrap repetition result in which $r_{\text {codend }}$ $\left(l, v_{\text {codend }}\right)$ and $\mathrm{nPop}_{l}$ were applied simultaneously in eq. 4 . Finally, based on the resulting bootstrap set, 95\% CIs were obtained for each of the indicators. All analyses of the exploitation pattern indicators were conducted using SELNET (Herrmann et al. 2012).

\section{Comparison with the gear currently used in the fishery}

To complete the answer to research question 3 and assess the performance of the four codend configurations tested in this study relative to the gear currently used in the Barents Sea, we first estimated the exploitation pattern indicators for the Sort-V and Flexigrid grid systems combined with a diamond mesh codend for cod, haddock, and redfish. We then compared these results to those obtained in the present study for the four codend configurations tested. The selectivity data used to estimate the indicators for cod and haddock with a Sort-V grid combined with a diamond mesh codend were obtained from Sistiaga et al. (2010), whereas the data for the Flexigrid and codend system for these two species were obtained from Brinkhof et al. (2020). Note that the codend used together with the Sort-V grid in Sistiaga et al. (2010) had a mesh size of $135 \mathrm{~mm}$, which was the minimum mesh size in the codend at the time. The selectivity data used for redfish were presented in Herrmann et al. (2013). As the exploitation pattern indicators depend on the fish population in the area at the time the trials are conducted $\left(\mathrm{nPop}_{l}\right)$, the $\mathrm{nPop}_{l}$ used to estimate the indicators for cod, haddock, and redfish with the grid systems was the same as that used to estimate the indicators for the four codend configurations tested in the present study.

The probability of retaining fish above the MLS and the discard ratio are two important indicators to consider when comparing the performance of different gear, as the former is a measure of the efficiency of the gear and the latter is a measure of the undersized fish caught with respect to the number of fish above the MLS caught. We used these two indicators to compare the performance of the four codend configurations tested in the present study with that of the Sort-V and Flexigrid grid sections combined with a $130 \mathrm{~mm}$ codend.

\section{Results}

\section{Overview of sea trials}

We conducted 31 hauls during the experimental period, 6 of them with the 128 and $137 \mathrm{~mm}$ codends in the standard configuration (without shortened lastridge ropes) and 25 with the same codends in the shortened lastridge configuration. In total, we measured 12938 cod, 12162 haddock, and 3119 redfish during the trials (Table 1).

\section{Size selectivity results}

The size selectivity analysis results showed primarily that the models used to represent the data for all four codend configurations tested for cod, haddock, and redfish were adequate. The Richard model was found to describe the data best in most cases. In all cases, the $p$ value for the model with the lowest AIC value among the models considered was $>0.05$, which indicates that the difference between the experimental points and the model used in every case could be coincidental (Table 2). This result was corroborated by the selectivity curves, which fitted the experimental data well in every case (Fig. 2).

\section{Effect of increasing mesh size on size selectivity}

For cod, haddock, and redfish, the L50 values estimated for the $128 \mathrm{~mm}$ codend with both the standard and the shortened lastridge configuration were always lower than those for the $137 \mathrm{~mm}$ codend with the same configuration (Table 2). A comparison of the selectivity curves and the corresponding delta plots between the 128 and $137 \mathrm{~mm}$ codends in the standard configuration also illustrate the difference between the codends for all three species (Fig. 3). When the curves were compared for the codends in the standard configuration, the differences observed were significant for a few length classes that included fish above and below the MLS for haddock but only for fish above the MLS for cod and redfish (Figs. $3 b, 3 f, 3 j$ ). However, when the codends were compared in the shortened lastridge configuration, the differences between the codends increased substantially for all three species. Not only was the difference larger, but it was also significant for a larger number of length classes. For all three species, the $128 \mathrm{~mm}$ codend with shortened lastridge ropes captured significantly more fish of length classes both above and below the MLS, although the number of length classes that differed between the codends was substantially larger for cod and haddock than for redfish (Figs. 3d, 3h, 3l).

\section{Effect of shortening lastridge ropes on size selectivity}

The L50 values estimated for the two codends in the shortened lastridge rope configuration were always higher than the equivalent in the standard configuration (Table 2). A comparison of the selectivity curves and the corresponding delta plots obtained for cod, haddock, and redfish with the codends in the standard configuration and the shortened lastridge rope configuration showed that in general, shortening the lastridge ropes decreased the retention probability for the smaller length classes (Fig. 4). For the $128 \mathrm{~mm}$ codend, shortening the lastridge ropes resulted in no significant decrease in the retention probability of cod, a slight but significant decrease for some length classes of haddock, and a more considerable and significant effect on redfish (Figs. $4 b, 4 f, 4 j$ ). For the $137 \mathrm{~mm}$ codend, on the other hand, shortening the lastridge ropes led to a more pronounced reduction over a larger range of length classes for all three species (Figs. $4 d, 4 h, 4 l$ ). For this codend, the effect was largest for redfish and similar for cod and haddock.

\section{Simulation of the experimental selectivity curves and} contribution of different meshes to size selectivity

The simulation results showed that for all four codend configurations and the three species included in the study, the experimental selectivity curves could be well explained by a combination of 
Table 1. Overview of the hauls conducted during the experimental sea trials and the numbers $(n)$ of cod, haddock, and redfish retained in the codend $(C)$ and codend cover $(C C)$ in each haul.

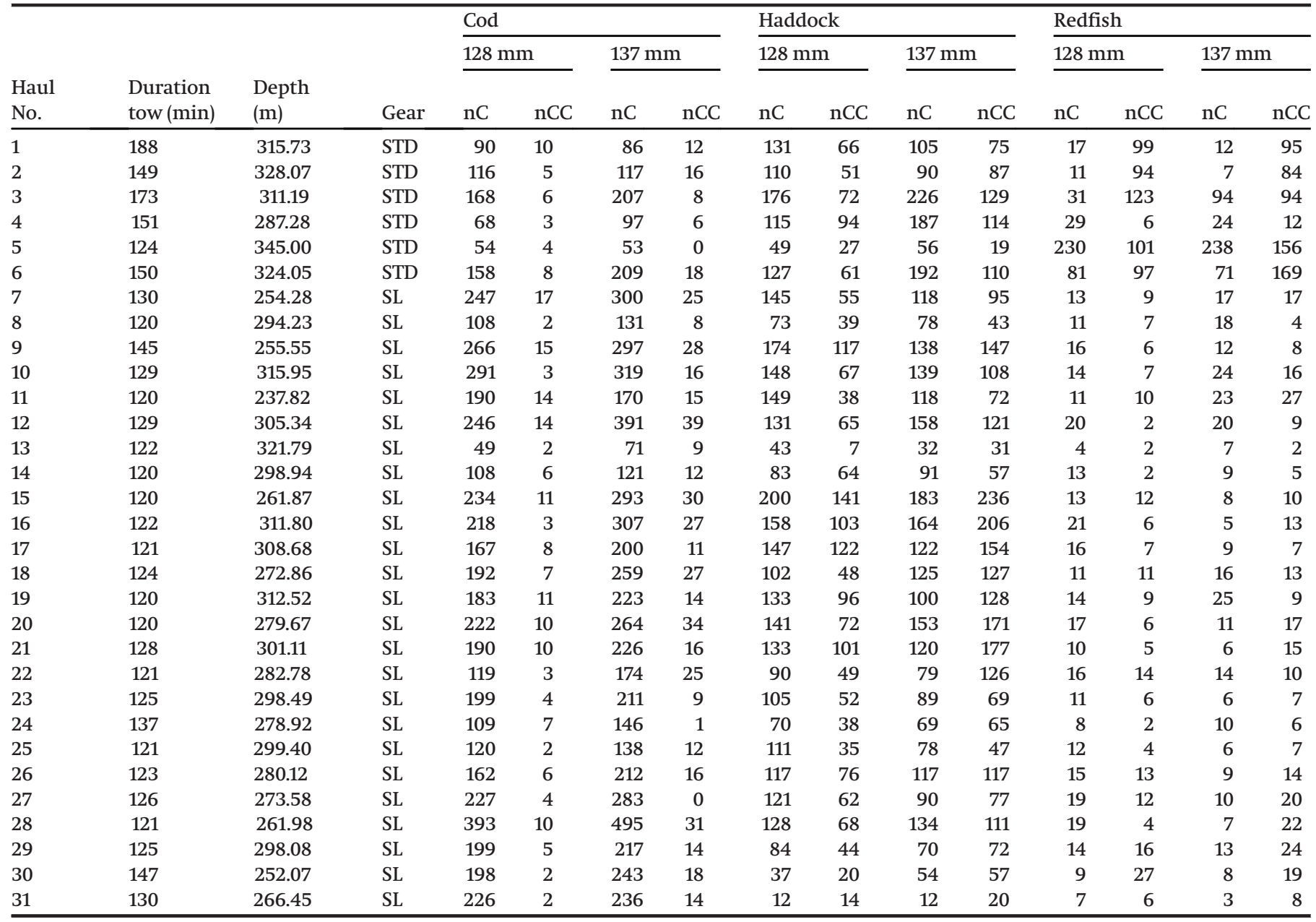

Note: STD is the standard configuration (nonshortened lastridge ropes), and SL is the codend with shortened lastridge ropes.

Table 2. Selection model, selectivity parameters, and fit statistics for the four codend configurations tested and the three species sampled during the sea trials.

\begin{tabular}{|c|c|c|c|c|c|c|c|c|c|}
\hline Species & Lastrige ropes & $\begin{array}{l}\text { Mesh } \\
\text { size }(\mathrm{mm})\end{array}$ & Model & $\mathrm{L} 50(\mathrm{~cm})$ & $\mathrm{SR}(\mathrm{cm})$ & $d$ & Deviance & df & $p$ \\
\hline \multirow[t]{3}{*}{ Cod } & Standard & 128 & Logit & $41.20(38.06-43.42)$ & $8.75(5.58-13.04)$ & - & 34.00 & 79 & $>0.999$ \\
\hline & & 137 & Richard & $44.29(41.25-47.07)$ & $12.28(8.43-16.61)$ & $0.19(0.10-0.42)$ & 39.17 & 82 & $>0.999$ \\
\hline & & 137 & Logit & $49.14(48.21-49.92)$ & $6.13(5.33-7.00)$ & 一 & 37.89 & 88 & $>0.999$ \\
\hline \multirow[t]{2}{*}{ Haddock } & Standard & 128 & Probit & $39.20(38.50-39.86)$ & $7.14(5.96-8.33)$ & - & 21.71 & 52 & 0.993 \\
\hline & & 137 & Richard & $41.07(39.61-42.32)$ & $6.75(4.95-7.86)$ & $0.63(0.30-1.60)$ & 30.30 & 49 & 0.984 \\
\hline \multirow[t]{4}{*}{ Redfish } & Standard & 128 & Richard & $32.77(31.38-34.93)$ & $6.38(4.21-8.51)$ & $0.60(0.13-1.37)$ & 37.09 & 35 & 0.373 \\
\hline & & 137 & Richard & $35.15(32.54-38.61)$ & $9.05(6.04-12.50)$ & $0.13(0.10-0.40)$ & 8.47 & 37 & 1.000 \\
\hline & Shortened & 128 & Richard & $38.57(37.17-39.64)$ & $7.60(5.55-10.06)$ & $0.19(0.10-0.44)$ & 41.60 & 39 & 0.355 \\
\hline & & 137 & Richard & $42.47(41.37-43.46)$ & $6.52(4.81-8.46)$ & $0.35(0.10-1.01)$ & 42.46 & 40 & 0.366 \\
\hline
\end{tabular}

Note: L50 is length of fish with 50\% probability of being retained, SR is the difference in length between fish with $75 \%$ and $25 \%$ probability of being retained, and $d$

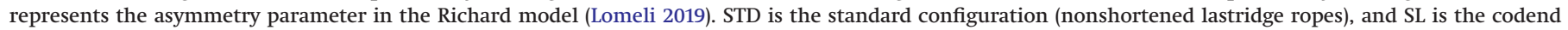
with shortened lastridge ropes. Values in parentheses represent 95\% confidence intervals.

contributions from different mesh sizes and opening angles. In every case, the simulated selectivity curve was within the CIs of the experimental selectivity curves (Fig. 5). Further, the potential contributions of the different meshes and mesh openings showed that in general, cod, haddock, and especially redfish were able to utilize more open meshes or slack meshes to escape when the codends with short lastridge ropes were used (Table 3). This result indicates that with this configuration the longitudinal forces in the codend meshes were lower, providing greater availability of the more open meshes and slack meshes. 
Fig. 2. Length-dependent retention probabilities for cod, haddock, and redfish with the four codend configurations tested during the trials. STD is the standard configuration (nonshortened lastridge ropes), and SL is the codend with shortened lastridge ropes. In each plot, the circles represent the experimental observations, the solid curve represents the models fitted to the data, and the dashed curves represent the $95 \%$ CIs. The grey line represents the population fished by the gear (codend + cover). The dashed vertical grey lines show the minimum legal size (MLS) for cod $(44 \mathrm{~cm})$, haddock $(40 \mathrm{~cm})$, and redfish $(32 \mathrm{~cm})$.
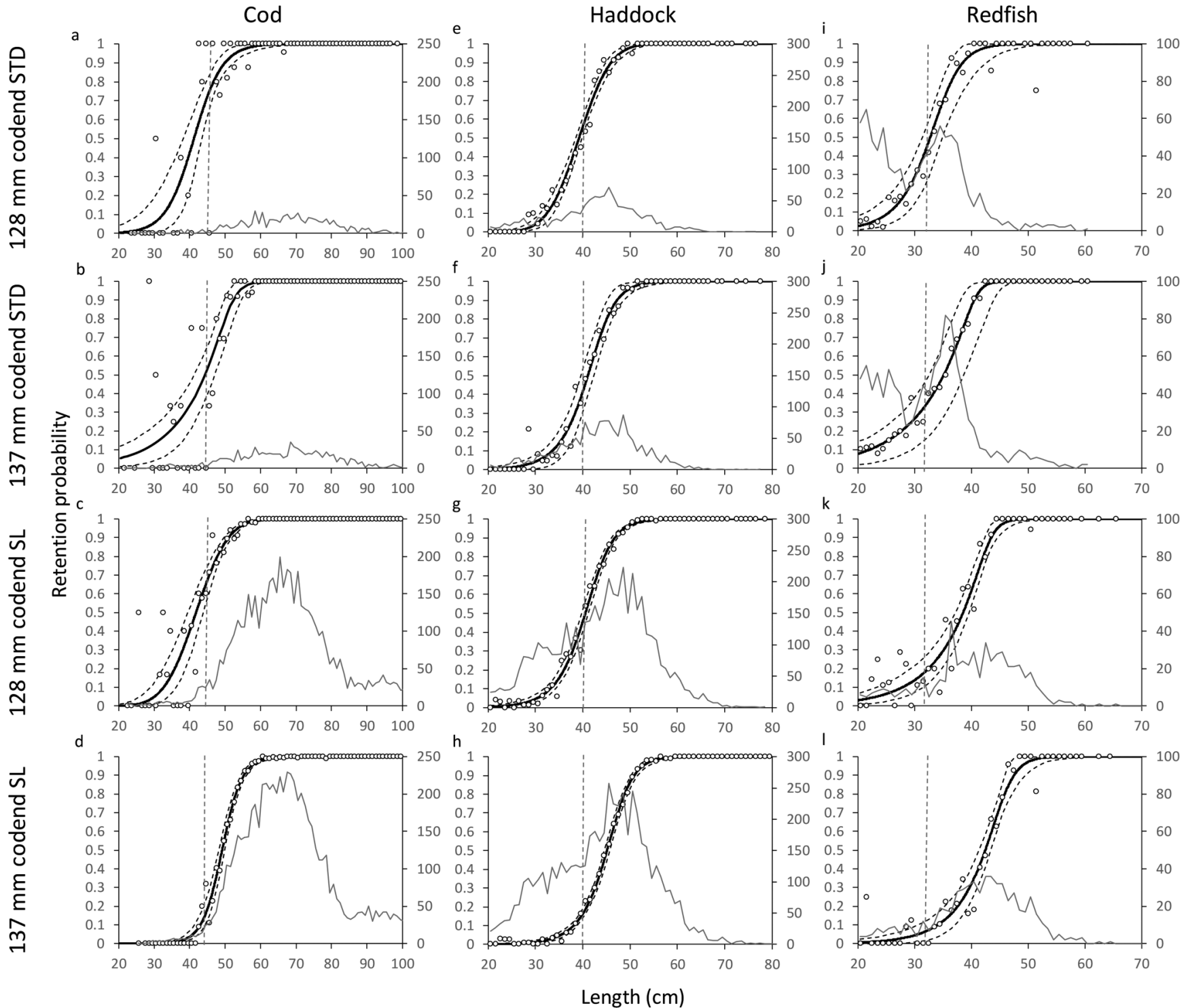

The simulations showed that when the $128 \mathrm{~mm}$ codend was employed, cod may have escaped through similar opening angles and mesh sizes independent of which gear configuration was used. For the $137 \mathrm{~mm}$ mesh codend, however, cod may have been able to use more of the larger meshes available and meshes with $10^{\circ}-20^{\circ}$ higher opening angles when the shortened lastridge configuration was used in the codend (Table 3). The simulation results showed a similar pattern for haddock. However, the meshes with opening angles of $40^{\circ}-50^{\circ}$ may have been more important for haddock than for cod, whereas meshes with opening angles of $20^{\circ}-30^{\circ}$ showed higher relevance for cod (Table 3). Finally, the simulation of the results obtained experimentally for redfish showed that compared to cod and haddock, redfish potentially have greater ability to utilize meshes with higher opening angles or slack meshes that are deformable upon escape. Shortening the lastridge ropes likely allowed redfish to make use of meshes with higher opening angles and especially slack meshes. Finally, the simulations estimated that when the 128 and $137 \mathrm{~mm}$ codends were fished in the shortened lastridge configuration, $46.95 \%$ and $62.77 \%$, respectively, of the redfish that escaped through the codend meshes may have done so through the largest meshes in the slack state available in the codend (Table 3 ).

\section{Exploitation pattern indicators for the four codend configurations tested}

Exploitation pattern indicators depend on the fish population in the fishing area at the time of the trials. Therefore, to conduct a fair comparison between the different codends tested, the indicators for the four codend configurations tested during the trials were estimated based on the length-frequencies of the fish population encountered during the whole trial period (Fig. 6).

For cod, the catch pattern indicators showed that the probability of catching fish under the MLS of $44 \mathrm{~cm}$ and the discard ratio decreased when we increased the mesh size from 128 to $137 \mathrm{~mm}$, but the decrease was only statistically significant for the shortened lastridge rope configuration. When comparing the two gear 
Fig. 3. Comparison of the $128 \mathrm{~mm}$ (black) and $137 \mathrm{~mm}$ (grey) codends tested in both the standard (STD) and the short lastridge (SL) configurations. Delta plots of the comparisons are also shown. The dashed curves represent the $95 \%$ CIs in each case. The dashed vertical grey lines show the MLS for cod $(44 \mathrm{~cm})$, haddock $(40 \mathrm{~cm})$, and redfish $(32 \mathrm{~cm})$.
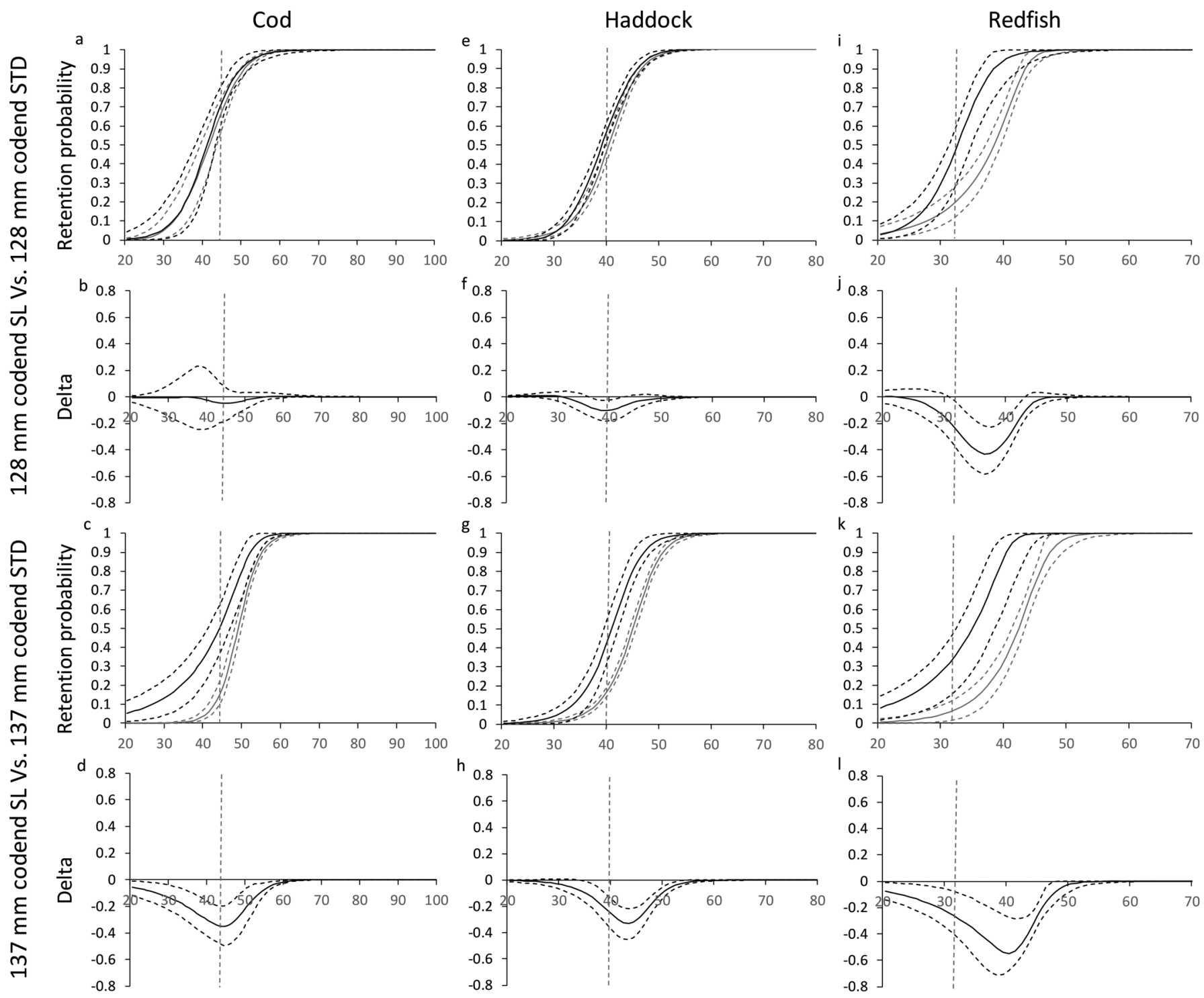

Length $(\mathrm{cm})$

configurations for the $128 \mathrm{~mm}$ codend, the gear change did not have a significant effect on either parameter. However, for the $137 \mathrm{~mm}$ codend, shortening the lastridge ropes significantly decreased the probability of capturing cod $<44 \mathrm{~cm}$ and the discard ratio, and the probability of retaining cod $>44 \mathrm{~cm}$ decreased from $97.4 \%$ to $94.1 \%$. Increasing the MLS to $50 \mathrm{~cm}$ increased the probability of retaining cod both below and above the MLS. The discard ratio increased significantly for all four configurations (Table 4).

For haddock, as for cod, increasing mesh size in the standard codend configuration had no significant effect on any of the parameters estimated. The discard ratio only decreased from $8.7 \%$ to $6.7 \%$, and although the probability of retaining fish $<40 \mathrm{~cm}$ decreased from $17.9 \%$ to $12.8 \%$, the reduction was not statistically significant. However, all three indicators differed significantly when the codends were compared in the shortened lastridge configuration. As for cod, increasing the MLS from 40 to $45 \mathrm{~cm}$ significantly increased the retention probability for haddock above and below the MLS and the discard ratio for all four configurations tested. For example, the discard ratio for the $128 \mathrm{~mm}$ codend in the standard configuration increased from $8.7 \%$ to $28.1 \%$ when the MLS was increased from 40 to $45 \mathrm{~cm}$.

For redfish, the probability of catching fish below or above MLS did not change significantly when the codend mesh size increased from 128 to $137 \mathrm{~mm}$ in either configuration. However, when we compared the two configurations with 128 or $137 \mathrm{~mm}$ codends, the probability of catching redfish below and above the MLS was substantially lower in the shortened lastridge configuration, and the reduction was statistically significant for the probability of catching redfish below the MLS for the $137 \mathrm{~mm}$ codend. The discard ratio did not differ significantly among any of the four codend configurations tested (Table 4).

\section{Comparison of the exploitation pattern indicators of the four codend configurations tested with those of the gear currently used in the fishery}

The exploitation pattern indicators for the Sort-V and Flexigrid grid systems combined with a diamond mesh codend (Table 5) 
Fig. 4. Comparison of the 128 and $137 \mathrm{~mm}$ codends in the standard (STD) configurations (black) and the configuration with shortened lastridge ropes (SL; grey). Delta plots of the comparisons are also shown. The dashed curves represent the $95 \%$ CIs in each case. The dashed vertical grey lines show the MLS for cod $(44 \mathrm{~cm})$, haddock $(40 \mathrm{~cm})$, and redfish $(32 \mathrm{~cm})$.
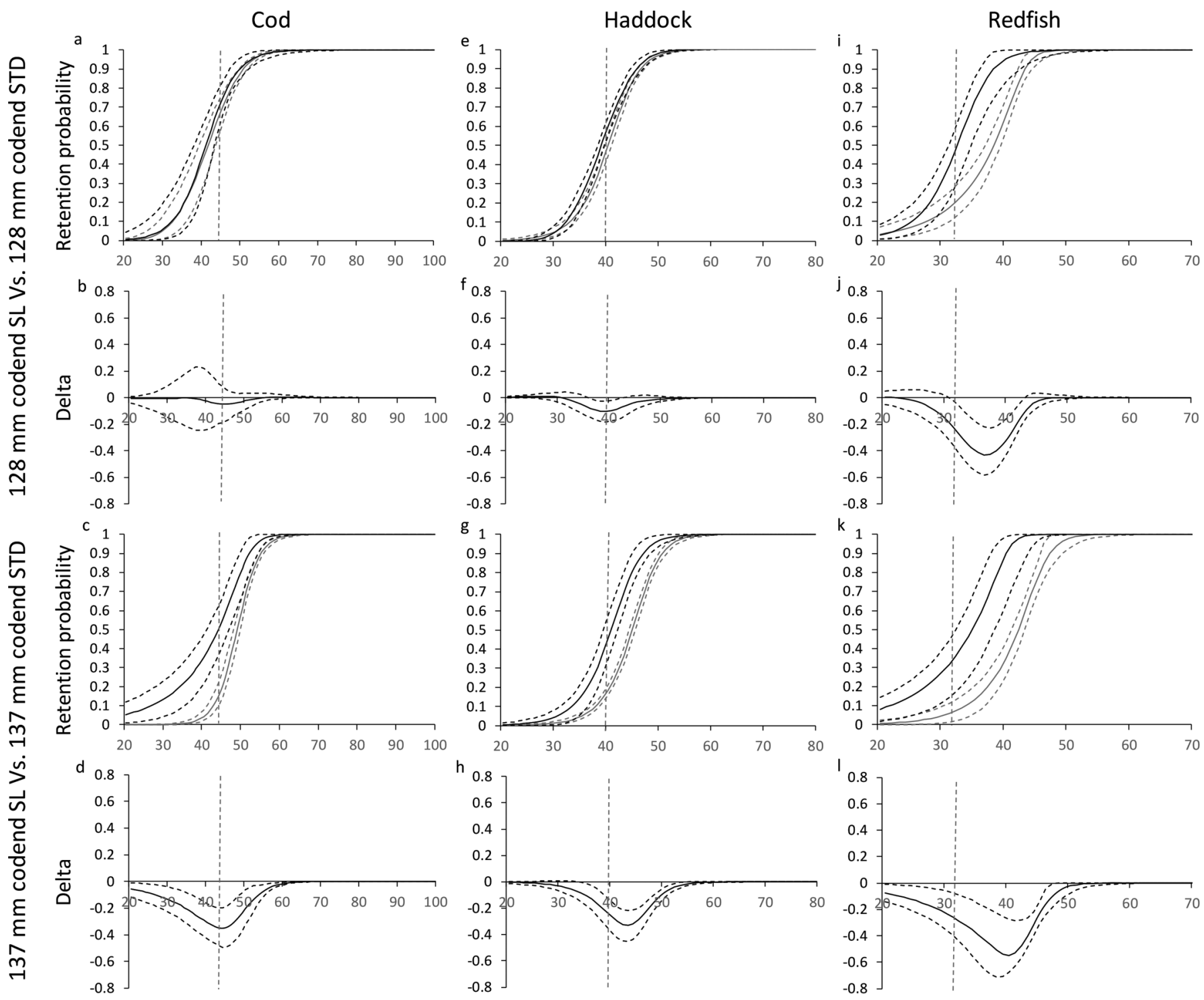

Length $(\mathrm{cm})$

were estimated based on the length-frequencies of the fish population encountered during the whole trial period (Fig. 6). The results for the grid systems showed that the probability of retaining fish under the MLS was low ( $<5 \%$ for cod, $<1 \%$ for haddock, and $<1 \%$ for redfish). Increasing the MLS to $50 \mathrm{~cm}$ for cod and $45 \mathrm{~cm}$ for haddock increased the probability of catching undersized cod to approximately $15 \%$ and $<3 \%$ for haddock. These increases were significant in both cases. The results also showed that while the retention probabilities for cod over MLS $\left(\mathrm{nP}^{+}\right)$with the Sort-V grid and Flexigrid were over $87 \%$ and $83 \%$, respectively, regardless of the MLS used, for haddock the retention probability with the grid systems could be as low as $24 \%$ and not higher than $47 \%$ (Table 5). With increasing MLS, the discard ratio increased by approximately $1 \%$ for cod for both grids and approximately $4 \%$ for haddock with the Sort-V grid and $130 \mathrm{~mm}$ codend, and the increase was statistically significant in both cases (Table 5). The retention probability for undersized redfish and the discard ratio with the Sort-V grid and codend system were low, but the retention probability for fish above the MLS was also low and under 30\% (Table 5).

Considering the current MLS for cod in the Barents Sea, the retention probability of commercial fish for all four codend configurations tested in this study was $>\mathbf{9 4 \%}$ in all cases, whereas retention probability was $87 \%$ and $83 \%$ for the Sort-V grid and Flexigrid systems, respectively. If the MLS was increased to $50 \mathrm{~cm}$ for cod, the retention probability for all four codend configurations tested would be $>96 \%$, whereas it would be $90 \%$ and $86 \%$ for the Sort-V grid and Flexigrid systems, respectively (Tables 4-5). Regardless of the MLS considered, the retention probability for cod with the four codend configurations tested was significantly higher than that for the two grid configurations (Fig. 7). The discard ratio for cod was $<1 \%$ for all six configurations when the MLS was $44 \mathrm{~cm}$ and $<5 \%$ when the MLS was increased to $50 \mathrm{~cm}$. Although the discard ratio differences were not large, they were significant among all codend configurations tested except the 
Fig. 5. Experimental (black) and simulated (purple) size-selection curves for the four codend configurations tested during the trials. Dashed curves (black) show the 95\% CIs. STD is the standard configuration (nonshortened lastridge ropes), and SL is the codend with shortened lastridge ropes. The red curves show selection curves simulated in FISHSELECT for meshes of $128 \mathrm{~mm}(a, c, e, g, i$, and $k)$ and $137 \mathrm{~mm}(b, d, f, h, j$, and $l)$ with opening angles of $20^{\circ}, 50^{\circ}$, and $80^{\circ}$. The blue curves show selection curves simulated in FISHSELECT for meshes of $134 \mathrm{~mm}(a, c, e, g, i$, and $k)$ and $142 \mathrm{~mm}(b, d, f, h, j$, and $l)$ with opening angles of $20^{\circ}, 50^{\circ}$, and $80^{\circ}$. The blue line to the right in each plot shows the selection curve for a slack mesh of $134 \mathrm{~mm}(a, c, e, g, i$, and $k)$ and $142 \mathrm{~mm}(b, d, f, h, j$, and $l)$ in each case. The dashed vertical grey lines show the MLS for cod $(44 \mathrm{~cm})$, haddock $(40 \mathrm{~cm})$, and redfish $(32 \mathrm{~cm})$. [Colour online.]

Cod

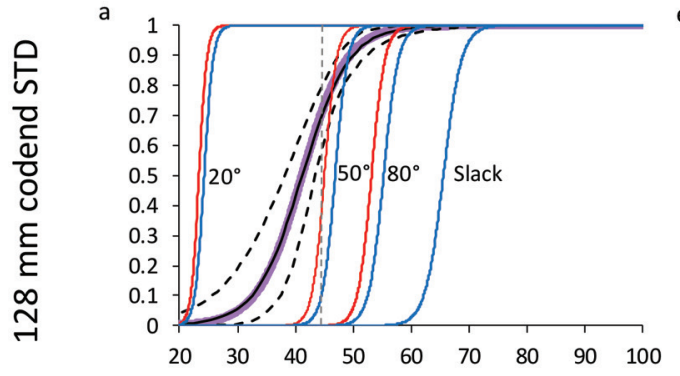

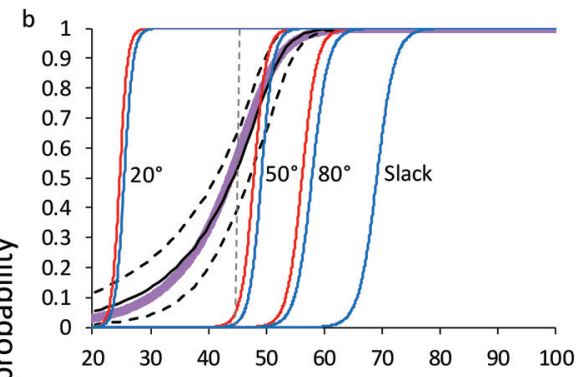
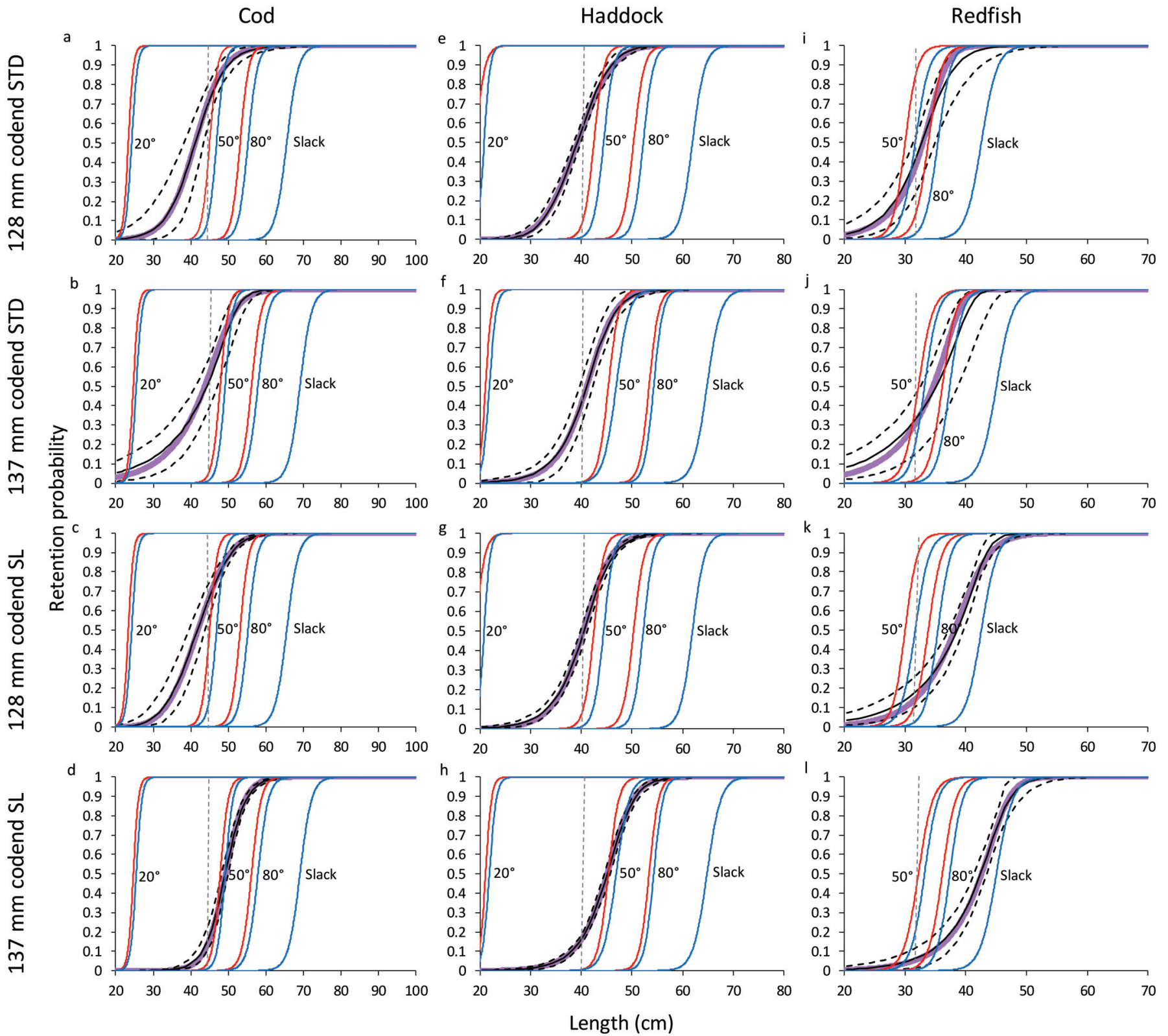

$137 \mathrm{~mm}$ codend with shortened lastridge ropes and the Sort-V grid and Flexigrid systems (Tables 4-5; Fig. 7).

At the MLS of $40 \mathrm{~cm}$, the retention probability for haddock for the four codend configurations tested varied between $70 \%$ and $91 \%$, whereas the values were $36 \%$ to $24 \%$ for the Sort-V and Flexigrid systems, respectively (Tables 4-5). The difference between the four codend configurations and the grids was significant (Fig. 7). Increasing the MLS to $45 \mathrm{~cm}$ increased the retention probability of haddock in all cases, with estimated values of $85 \%-97 \%$ for the four codend configurations tested, $47 \%$ for the Sort-V system, and $31 \%$ for the Flexigrid system (Tables 4-5). The difference between all four codends and the two grid systems was still statistically significant
(Fig. 7). However, the discard ratio was significantly higher for the test codends than for the two grid systems in every case, regardless of the MLS considered. At the MLS of $40 \mathrm{~cm}$, the discard ratio for the test codends never exceeded $9 \%$, but increasing the MLS to $45 \mathrm{~cm}$ resulted in a $28 \%$ discard ratio for the $128 \mathrm{~mm}$ codend in the standard configuration (Tables 4-5; Fig. 7).

The retention probability for redfish $>32 \mathrm{~cm}$ was significantly higher for the $128 \mathrm{~mm}$ codend and the $137 \mathrm{~mm}$ codend in the standard configuration compared to the Sort-V system, because the lower confidence limit in these three cases does not overlap with the upper confidence limit for the Sort-V system. The discard ratio was substantially lower with the Sort-V grid than with 


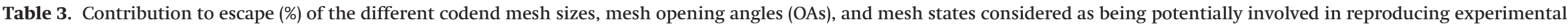
data for each of the four codends tested during the trials for cod, haddock, and redfish.

\begin{tabular}{|c|c|c|c|c|c|c|c|c|c|c|c|c|c|c|c|c|c|c|c|c|c|c|c|}
\hline \multicolumn{8}{|l|}{ Cod } & \multicolumn{8}{|l|}{ Haddock } & \multicolumn{8}{|l|}{ Redfish } \\
\hline & & \multicolumn{2}{|c|}{$\begin{array}{l}128 \mathrm{~mm} \\
\text { codend }\end{array}$} & \multirow[b]{3}{*}{$\begin{array}{l}\text { Mesh } \\
\text { size (mm) }\end{array}$} & \multirow[b]{3}{*}{$\mathrm{OA}$} & \multicolumn{2}{|c|}{$\begin{array}{l}137 \mathrm{~mm} \\
\text { codend }\end{array}$} & \multirow[b]{3}{*}{$\begin{array}{l}\text { Mesh } \\
\text { size (mm) }\end{array}$} & \multirow[b]{3}{*}{$\mathrm{OA}$} & \multicolumn{2}{|c|}{$\begin{array}{l}128 \mathrm{~mm} \\
\text { codend }\end{array}$} & \multirow[b]{3}{*}{$\begin{array}{l}\text { Mesh } \\
\text { size }(\mathrm{mm})\end{array}$} & \multirow[b]{3}{*}{$\mathrm{OA}$} & \multicolumn{2}{|c|}{$\begin{array}{l}137 \mathrm{~mm} \\
\text { codend }\end{array}$} & \multirow[b]{3}{*}{$\begin{array}{l}\text { Mesh } \\
\text { size }(\mathrm{mm})\end{array}$} & \multirow[b]{3}{*}{$\mathrm{OA}$} & \multicolumn{2}{|c|}{$\begin{array}{l}128 \mathrm{~mm} \\
\text { codend }\end{array}$} & \multirow[b]{3}{*}{$\begin{array}{l}\text { Mesh } \\
\text { size (mm) }\end{array}$} & \multirow[b]{3}{*}{$\mathrm{OA}$} & \multicolumn{2}{|c|}{$\begin{array}{l}137 \mathrm{~mm} \\
\text { codend }\end{array}$} \\
\hline & & STD & SL & & & STD & SL & & & STD & SL & & & STD & SL & & & STD & SL & & & STD & SL \\
\hline $\begin{array}{l}\text { Mesh } \\
\text { size (mm) }\end{array}$ & $\mathrm{OA}$ & & & & & & & & & & & & & & & & & & & & & & \\
\hline 128 & $10^{\circ}$ & - & - & 137 & $10^{\circ}$ & - & - & 128 & $10^{\circ}$ & - & - & 137 & $10^{\circ}$ & - & - & 128 & $10^{\circ}$ & - & - & 137 & $10^{\circ}$ & - & - \\
\hline 128 & $20^{\circ}$ & - & - & 137 & $20^{\circ}$ & 5.794 & - & 128 & $20^{\circ}$ & - & - & 137 & $20^{\circ}$ & 0.45 & - & 128 & $20^{\circ}$ & - & - & 137 & $20^{\circ}$ & - & - \\
\hline 128 & $30^{\circ}$ & 9.394 & 7.812 & 137 & $30^{\circ}$ & 9.635 & - & 128 & $30^{\circ}$ & 4.636 & 2.420 & 137 & $30^{\circ}$ & 0.028 & 0.928 & 128 & $30^{\circ}$ & 3.25 & - & 137 & $30^{\circ}$ & 15.26 & - \\
\hline 128 & $40^{\circ}$ & 18.789 & 17.135 & 137 & $40^{\circ}$ & 12.45 & 2.422 & 128 & $40^{\circ}$ & 25.78 & 20.773 & 137 & $40^{\circ}$ & 18.79 & 3.203 & 128 & $40^{\circ}$ & 9.704 & 9.828 & 137 & $40^{\circ}$ & 1.616 & 4.843 \\
\hline 128 & $50^{\circ}$ & 17.363 & 14.640 & 137 & $50^{\circ}$ & 13.13 & 19.061 & 128 & $50^{\circ}$ & 23.95 & 28.100 & 137 & $50^{\circ}$ & 26.73 & 24.952 & 128 & $50^{\circ}$ & 18.91 & 0.001 & 137 & $50^{\circ}$ & 2.835 & 0.382 \\
\hline 128 & $60^{\circ}$ & 1.919 & 4.549 & 137 & $60^{\circ}$ & 7.641 & 21.172 & 128 & $60^{\circ}$ & 2.089 & 1.184 & 137 & $60^{\circ}$ & 1.589 & 12.049 & 128 & $60^{\circ}$ & $5 \mathrm{E}-04$ & 0.006 & 137 & $60^{\circ}$ & $6 \mathrm{E}-04$ & 0.013 \\
\hline 128 & $70^{\circ}$ & 0.284 & 0.692 & 137 & $70^{\circ}$ & 2.137 & 0.213 & 128 & $70^{\circ}$ & 1.092 & 2.207 & 137 & $70^{\circ}$ & 0.112 & 0.648 & 128 & $70^{\circ}$ & 0.004 & 0.002 & 137 & $70^{\circ}$ & 0.743 & 0.024 \\
\hline 128 & $80^{\circ}$ & 0.001 & 0.081 & 137 & $80^{\circ}$ & - & 0.000 & 128 & $80^{\circ}$ & - & - & 137 & $80^{\circ}$ & - & 0.373 & 128 & $80^{\circ}$ & 1.072 & 0.003 & 137 & $80^{\circ}$ & 1.904 & 0.379 \\
\hline 128 & $90^{\circ}$ & - & 0.001 & 137 & $90^{\circ}$ & - & 0.001 & 128 & $90^{\circ}$ & - & - & 137 & $90^{\circ}$ & - & 0.085 & 128 & $90^{\circ}$ & 0.009 & 0.000 & 137 & $90^{\circ}$ & 0.536 & 0.069 \\
\hline 134 & $10^{\circ}$ & - & - & 142 & $10^{\circ}$ & - & - & 134 & $10^{\circ}$ & - & - & 142 & $10^{\circ}$ & - & - & 134 & $10^{\circ}$ & - & - & 142 & $10^{\circ}$ & - & - \\
\hline 134 & $20^{\circ}$ & - & - & 142 & $20^{\circ}$ & 7.958 & - & 134 & $20^{\circ}$ & - & - & 142 & $20^{\circ}$ & 0.109 & - & 134 & $20^{\circ}$ & - & - & 142 & $20^{\circ}$ & - & - \\
\hline 134 & $30^{\circ}$ & 18.086 & 16.743 & 142 & $30^{\circ}$ & 9.43 & - & 134 & $30^{\circ}$ & 5.32 & 4.671 & 142 & $30^{\circ}$ & 13.93 & 3.921 & 134 & $30^{\circ}$ & 3.676 & - & 142 & $30^{\circ}$ & 4.754 & - \\
\hline 134 & $40^{\circ}$ & 16.938 & 16.099 & 142 & $40^{\circ}$ & 12.57 & 20.814 & 134 & $40^{\circ}$ & 20.86 & 19.950 & 142 & $40^{\circ}$ & 31.81 & 24.213 & 134 & $40^{\circ}$ & 5.827 & 6.097 & 142 & $40^{\circ}$ & 13.73 & 1.041 \\
\hline 134 & $50^{\circ}$ & 7.556 & 12.620 & 142 & $50^{\circ}$ & 11.33 & 19.759 & 134 & $50^{\circ}$ & 9.345 & 14.186 & 142 & $50^{\circ}$ & 4.9 & 24.454 & 134 & $50^{\circ}$ & 1.747 & 0.002 & 142 & $50^{\circ}$ & 0.107 & 0.001 \\
\hline 134 & $60^{\circ}$ & 1.656 & 1.299 & 142 & $60^{\circ}$ & 7.928 & 9.095 & 134 & $60^{\circ}$ & 6.924 & 6.507 & 142 & $60^{\circ}$ & 0.513 & 1.013 & 134 & $60^{\circ}$ & 0.002 & 0.007 & 142 & $60^{\circ}$ & 0.083 & 0.016 \\
\hline 134 & $70^{\circ}$ & 2.925 & 3.127 & 142 & $70^{\circ}$ & - & 1.452 & 134 & $70^{\circ}$ & - & - & 142 & $70^{\circ}$ & 1.042 & 0.170 & 134 & $70^{\circ}$ & 26.93 & 3.646 & 142 & $70^{\circ}$ & 24.49 & 2.013 \\
\hline 134 & $80^{\circ}$ & 5.091 & 5.201 & 142 & $80^{\circ}$ & - & 6.008 & 134 & $80^{\circ}$ & - & - & 142 & $80^{\circ}$ & - & 0.830 & 134 & $80^{\circ}$ & 26.87 & 23.173 & 142 & $80^{\circ}$ & 25.25 & 9.951 \\
\hline 134 & $90^{\circ}$ & - & - & 142 & $90^{\circ}$ & - & - & 134 & $90^{\circ}$ & - & - & 142 & $90^{\circ}$ & - & 3.162 & 134 & $90^{\circ}$ & 1.989 & 10.279 & 142 & $90^{\circ}$ & 8.688 & 18.492 \\
\hline 134 & Slack & - & - & 142 & Slack & - & - & 134 & Slack & - & - & 142 & Slack & - & - & 134 & Slack & - & 46.950 & 142 & Slack & - & 62.77 \\
\hline
\end{tabular}

Note: STD is the standard configuration (non-shortened lastridge ropes), and SL is the codend with shortened lastridge ropes. 
Fig. 6. Size distribution of cod, haddock, and redfish populations encountered during the experimental trials. The vertical dashed grey lines show the MLS for each species. The black dashed lines show the $95 \%$ confidence intervals for the variation in the populations encountered for each species.
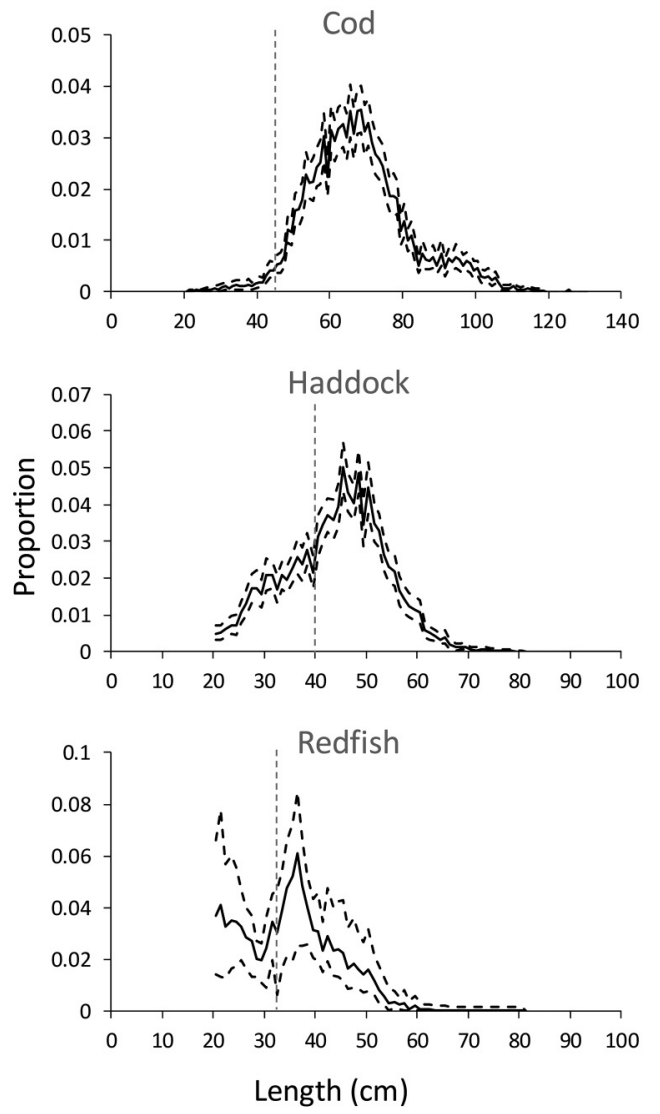

all codend configurations except for the $137 \mathrm{~mm}$ codend with shortened lastridge ropes. However, the difference was not statistically significant in any of the cases (Fig. 7).

\section{Discussion}

In this study, we compared catch patterns for two diamond mesh codends with different mesh sizes in a standard and a shortened lastridge configuration. The results demonstrated that both increasing mesh size from 128 to $137 \mathrm{~mm}$ and shortening the lastridge ropes for both codends, so that they were $15 \%$ shorter than the stretched codend netting, can change the selection properties of the codend for cod, haddock, and redfish (Figs. 3-4). The effect of mesh size was a consequence of the fact that physically larger fish are able to penetrate larger meshes. That both codends had the same number of free meshes around but different mesh size could also have contributed to the differences observed due to differences in codend circumference, which have earlier been demonstrated potentially affect codend size selectivity (Sala and Lucchetti 2011). The selectivity changes caused by shortening the lastridge ropes occurred because this modification removes the tension from the netting generated by the accumulation of fish inside the codend, which results in slacker and more open meshes (Herrmann $2005 a, 2005 b)$. The effect on selectivity of increasing mesh size was more pronounced for the codends in the shortened lastridge configuration than in the standard configuration. Because shortening lastridge ropes contributes to more slack meshes with higher opening angles in the codend, we expected a larger effect of changing codend mesh size on size selection with this configuration compared to the standard configuration. The effect on the sizeselection properties of the diamond mesh in the shortened lastridge configuration was clear for both codends, but it was more pronounced for the $137 \mathrm{~mm}$ codend. As the hanging ratio was the same for both codends, this difference likely was due to the stiff netting material used, which could have reduced the effect of the shortened lastridge ropes for the smaller mesh size.

The simulation carried out using the existing FISHSELECT models for cod, haddock, and redfish (Sistiaga et al. 2011; Herrmann et al. 2012) showed that it is indeed possible to explain the selectivity results obtained for these three species and the four diamond mesh codend configurations tested in our study. The results indicate that when using shortened lastridge codends, the availability of meshes with high opening angles is larger and all three species investigated are able to escape through these meshes. The largest contributions were for mesh opening angles of $40^{\circ}-60^{\circ}$ for cod and haddock and $80^{\circ}-90^{\circ}$ for redfish. It is unclear why the largest contribution to size selectivity for redfish changed from nearly square meshes when using the standard configuration to slack meshes when using the short lastridge configuration. Redfish is a robust fish that tries so hard to squeeze itself through meshes that it often gets stuck (Isaksen and Valdemarsen 1986; ICES 2012). However, considering the stiffness of the material used in the codends (single braided polyethylene hotmelt twine, $\emptyset 8 \mathrm{~mm}$ ), it is difficult to understand how the meshes could be slack enough to deform and allow redfish to pass through them. The experimental design and data analysis in this study do not allow us to provide a clear explanation for the observed redfish selectivity results other than those already discussed.

In recent years, the use of exploitation pattern indicators has gained popularity in size selectivity studies (Santos et al. 2016; Sala et al. 2017; Cheng et al. 2019; Kalogirou et al. 2019; Melli et al. 2020) because they provide a good picture of how the gear performs with respect to the management objectives and alternative catch pattern objectives in the fishery. Considering the MLS for cod, haddock, and redfish, the estimated indicator values showed that the tested codend configurations performed quite differently. While the $137 \mathrm{~mm}$ codend with shortened lastridge ropes retained $<5 \%$ of undersized fish of all three species and $>94 \%$ of the cod above MLS, it resulted in a loss of $\sim 30 \%$ and $\sim 60 \%$ of commercial haddock and redfish, respectively. On the other hand, reducing the mesh size to $128 \mathrm{~mm}$ for the same codend configuration reduced the loss of commercial haddock and redfish to $13 \%$ and $40 \%$, respectively, but the catch of undersized cod with this codend configuration increased to over $30 \%$. The indicator results obtained with the $137 \mathrm{~mm}$ shortened lastridge codend fit with the goals of the fleet of keeping haddock and cod larger than 45 and $50 \mathrm{~cm}$, respectively, whereas using the $128 \mathrm{~mm}$ codend captured lower value haddock and cod. However, the shortened lastridge $137 \mathrm{~mm}$ codend that caught $<5 \%$ of cod below the MLS also caught over $25 \%$ of fish below $50 \mathrm{~cm}$. Overall, these indicator results illustrate the challenge of multispecies fisheries and the difficulty of finding optimal gear solutions that provide satisfactory and efficient results for different species simultaneously. Our results also show that a change of 5 or $6 \mathrm{~cm}$ in the legal or desired minimum size of a certain species can notably change the performance of the gear with respect to this new potential goal. However, we must stress that the indicators depend on the specific population the gear encounters for each species during the trials and that selectivity estimates can provide a more general picture of the selective performance of the gear tested.

Compared to the mandatory sorting grid and codend gear used in the Barents Sea gadoid fishery, all codend configurations tested in this study retained significantly more commercial-sized cod and had a discard ratio that was only marginally larger. The pattern was similar when the minimum size was for cod was set at $50 \mathrm{~cm}$, but in this case the retention of commercial cod was substantially larger and the discard ratio was always $<5 \%$. From 
Table 4. Exploitation pattern indicator values for the four codend configurations tested and the three species sampled during the sea trials.

\begin{tabular}{|c|c|c|c|c|}
\hline \multirow[b]{2}{*}{ Indicator } & \multicolumn{2}{|l|}{$\underline{\text { Standard }}$} & \multicolumn{2}{|l|}{$\underline{\text { Short lastridges }}$} \\
\hline & $128 \mathrm{~mm}$ & $137 \mathrm{~mm}$ & $128 \mathrm{~mm}$ & $137 \mathrm{~mm}$ \\
\hline \multicolumn{5}{|l|}{ Cod } \\
\hline $\mathrm{nP}^{-} 44 \mathrm{~cm}(\%)$ & $35.5(22.1-50.3)$ & $30.1(18.1-41.8)$ & $33.2(22.7-44.0)$ & $4.4(2.5-7.3)$ \\
\hline $\mathrm{nP}^{+} 44 \mathrm{~cm}(\%)$ & $98.3(97.0-99.2)$ & 97.4 (95.5-98.7) & $98.1(97.6-98.6)$ & $94.1(93.0-95.0)$ \\
\hline nDiscard (\%) & $0.9(0.5-1.4)$ & $0.8(0.4-1.1)$ & $0.8(0.5-1.2)$ & $0.1(0.1-0.2)$ \\
\hline $\mathrm{nP}^{-} 50 \mathrm{~cm}(\%)$ & $66.2(57.8-74.1)$ & $54.3(41.4-65.6)$ & $62.9(55.1-70.4)$ & $26.3(20.2-33.0)$ \\
\hline $\mathrm{nP}^{+} 50 \mathrm{~cm}(\%)$ & $99.1(98.0-99.8)$ & $98.8(97.6-99.7)$ & $99.1(98.8-99.4)$ & $96.8(96.1-97.5)$ \\
\hline nDiscard (\%) & $4.8(4.1-5.8)$ & $4.0(3.0-4.9)$ & $4.6(3.8-5.4)$ & $2.0(1.5-2.5)$ \\
\hline \multicolumn{5}{|l|}{ Haddock } \\
\hline $\mathrm{nP}^{-} 40 \mathrm{~cm}(\%)$ & $17.9(14.1-22.0)$ & $12.8(6.6-18.0)$ & $14.2(11.7-17.4)$ & $4.4(3.2-5.7)$ \\
\hline $\mathrm{nP}^{+} 40 \mathrm{~cm}(\%)$ & $90.6(88.1-92.9)$ & $86.2(82.0-91.2)$ & $87.8(85.7-89.8)$ & $70.0(67.1-72.9)$ \\
\hline nDiscard (\%) & $8.7(6.7-10.5)$ & $6.7(3.6-9.1)$ & $7.2(5.9-8.8)$ & $2.9(2.1-3.9)$ \\
\hline $\mathrm{nP}^{-} 45 \mathrm{~cm}(\%)$ & 37.5 (33.9-41.7) & $30.3(23.7-37.0)$ & $32.6(29.3-36.7)$ & 13.9 (12.1-15.9) \\
\hline $\mathrm{nP}^{+} 45 \mathrm{~cm}(\%)$ & $96.8(94.9-98.3)$ & $94.8(92.0-98.3)$ & 95.5 (94.5-96.5) & $83.9(81.4-86.2)$ \\
\hline nDiscard (\%) & $28.1(25.2-31.1)$ & $24.4(19.9-28.7)$ & $25.6(22.6-28.5)$ & $14.3(12.4-16.4)$ \\
\hline \multicolumn{5}{|l|}{ Redfish } \\
\hline $\mathrm{nP}^{-} 32 \mathrm{~cm}(\%)$ & 13.8 (5.7-22.9) & $16.8(5.9-25.7)$ & $8.1(3.5-14.1)$ & $2.3(0.3-5.4)$ \\
\hline $\mathrm{nP}^{+} 32 \mathrm{~cm}(\%)$ & 85.4 (72.0-94.4) & $75.4(56.7-89.8)$ & $60.4(50.6-75.6)$ & $41.3(30.2-57.9)$ \\
\hline nDiscard (\%) & $8.6(3.7-14.1)$ & $11.5(4.4-17.7)$ & $7.3(2.9-12.1)$ & $3.2(0.4-7.1)$ \\
\hline
\end{tabular}

Note: Indicator values for cod are shown for MLS of 44 and $50 \mathrm{~cm}$; indicator values for haddock are shown for MLS of 40 and $45 \mathrm{~cm}$; and indicator values for redfish are shown for MLS of $32 \mathrm{~cm}$.

Table 5. Exploitation pattern indicator values obtained for two grid and codend gear configurations used in the fishery today.

\begin{tabular}{|c|c|c|}
\hline Indicator & Sort- $\mathrm{V}+$ codend & Flexigrid + codend \\
\hline \multicolumn{3}{|l|}{ Cod } \\
\hline $\mathrm{nP}^{-} 44 \mathrm{~cm}(\%)$ & $4.6(2.8-7.4)$ & $3.7(1.7-7.0)$ \\
\hline $\mathrm{nP}^{+} 44 \mathrm{~cm}(\%)$ & $87.2(84.5-89.4)$ & $83.1(79.0-86.2)$ \\
\hline nDiscard (\%) & $0.1(0.1-0.2)$ & $0.1(0.1-0.2)$ \\
\hline $\mathrm{nP}^{-} 50 \mathrm{~cm}(\%)$ & $16.0(12.5-20.4)$ & $14.9(9.7-20.6)$ \\
\hline $\mathrm{nP}^{+} 50 \mathrm{~cm}(\%)$ & $90.4(87.9-92.4)$ & $86.1(82.1-89.1)$ \\
\hline nDiscard (\%) & $1.3(1.0-1.7)$ & $1.3(0.9-1.7)$ \\
\hline \multicolumn{3}{|l|}{ Haddock } \\
\hline $\mathrm{nP}^{-} 40 \mathrm{~cm}(\%)$ & $0.5(0.2-0.9)$ & $0.2(0.1-0.5)$ \\
\hline $\mathrm{nP}^{+} 40 \mathrm{~cm}(\%)$ & $35.9(31.3-40.0)$ & $23.7(20.3-27.7)$ \\
\hline nDiscard (\%) & $0.7(0.3-1.2)$ & $0.4(0.1-0.9)$ \\
\hline $\mathrm{nP}^{-} 45 \mathrm{~cm}(\%)$ & $2.2(1.5-3.0)$ & $0.9(0.4-1.6)$ \\
\hline $\mathrm{nP}^{+} 45 \mathrm{~cm}(\%)$ & $46.9(41.4-51.7)$ & $31.5(27.2-36.2)$ \\
\hline nDiscard (\%) & $4.5(3.2-6.1)$ & $2.7(1.1-4.7)$ \\
\hline \multicolumn{3}{|l|}{ Redfish } \\
\hline $\mathrm{nP}^{-} 32 \mathrm{~cm}(\%)$ & $0.1(0.0-2.6)$ & - \\
\hline $\mathrm{nP}^{+} 32 \mathrm{~cm}(\%)$ & $29.1(20.0-45.0)$ & - \\
\hline nDiscard (\%) & $0.2(0.0-4.7)$ & - \\
\hline
\end{tabular}

Note: The minimum mesh size in the codend, which was $135 \mathrm{~mm}$ in 2010, is now $130 \mathrm{~mm}$. The selectivity data for the estimation of the indicators are based on the data presented in Sistiaga et al. (2010), Herrmann et al. (2012), and Brinkhof et al. (2020). The populations used for all three species are those shown in Figure 6. Indicator values for cod are shown for MLS of 44 and $50 \mathrm{~cm}$; indicator values for haddock are shown for MLS of 40 and $45 \mathrm{~cm}$; and indicator values for redfish are shown for MLS of $32 \mathrm{~cm}$.

this perspective, the diamond mesh codends, and especially the $137 \mathrm{~mm}$ codend, with shortened lastridge ropes resulted in more satisfactory selection than the grid and codend configurations used in the fishery today. The patterns observed for haddock were similar to those for cod, although for this species the differences between the grid systems and the codends tested in the present study were more pronounced. It is clear from the results that removing the grids from the fishery would significantly increase the retention of haddock over the current MLS and haddock above $45 \mathrm{~cm}$. However, the discard ratio for the codends tested was much larger than for the grid and codend configurations. For three of the four codends tested when the MLS was set at $45 \mathrm{~cm}, 25 \%$ of the catch would be below this size. Only the $137 \mathrm{~mm}$ codend with shortened lastridge ropes was able to keep the discard ratio for haddock below $15 \%$. For redfish, the differences between the Sort-V grid system and the tested codends were similar to but not as clear as those for cod and haddock, so it is more difficult to draw a conclusion about the extent to which the fishery would benefit from removing the grids and using any of the different types of codends tested in this study.

In general, the indicator results obtained and our comparison of the performance of the compulsory grid systems used in the Barents Sea today with the codends tested in our study showed that in many cases shortened lastridge codends can provide a better catch pattern than the grid system for the species of interest. Particularly for cod, and to a large extent for haddock, the $137 \mathrm{~mm}$ codend with shortened lastridge ropes resulted in a significantly higher retention of fish above the MLS with an insignificant or small increase in the discard ratio compared to the compulsory grid system. Therefore, in terms of size selection, our results show that a codend with shortened lastridge ropes is an alternative to the grid and codend gear currently required in the Barents Sea demersal trawl fishery.

Despite the positive selectivity results obtained with the codends in the shortened lastridge configuration and their maneuverability and encouraging performance compared to the grid systems, other aspects need to be considered. For example, it is important to understand how and when fish escape through the selection device. Selectivity through codend meshes is highly dependent on fish behavior, meaning that fish must actively swim through the meshes to escape. While species such as haddock are active in the 
Fig. 7. Values for the indicators $\mathrm{nP}^{+}$(individuals above MLS in \%) and discard ratio (\%) for cod for MLS of 44 and $50 \mathrm{~cm}$, for haddock for MLS of 40 and $45 \mathrm{~cm}$, and for redfish for $32 \mathrm{~cm}$ (Tables 4-5) for the four codends tested in this study and the two grid systems used today in the Barents Sea bottom trawl gadoid fishery. STD is the standard configuration (nonshortened lastridge ropes), and SL is the codend with shortened lastridge ropes. The abscissa labels are consistent for each column.

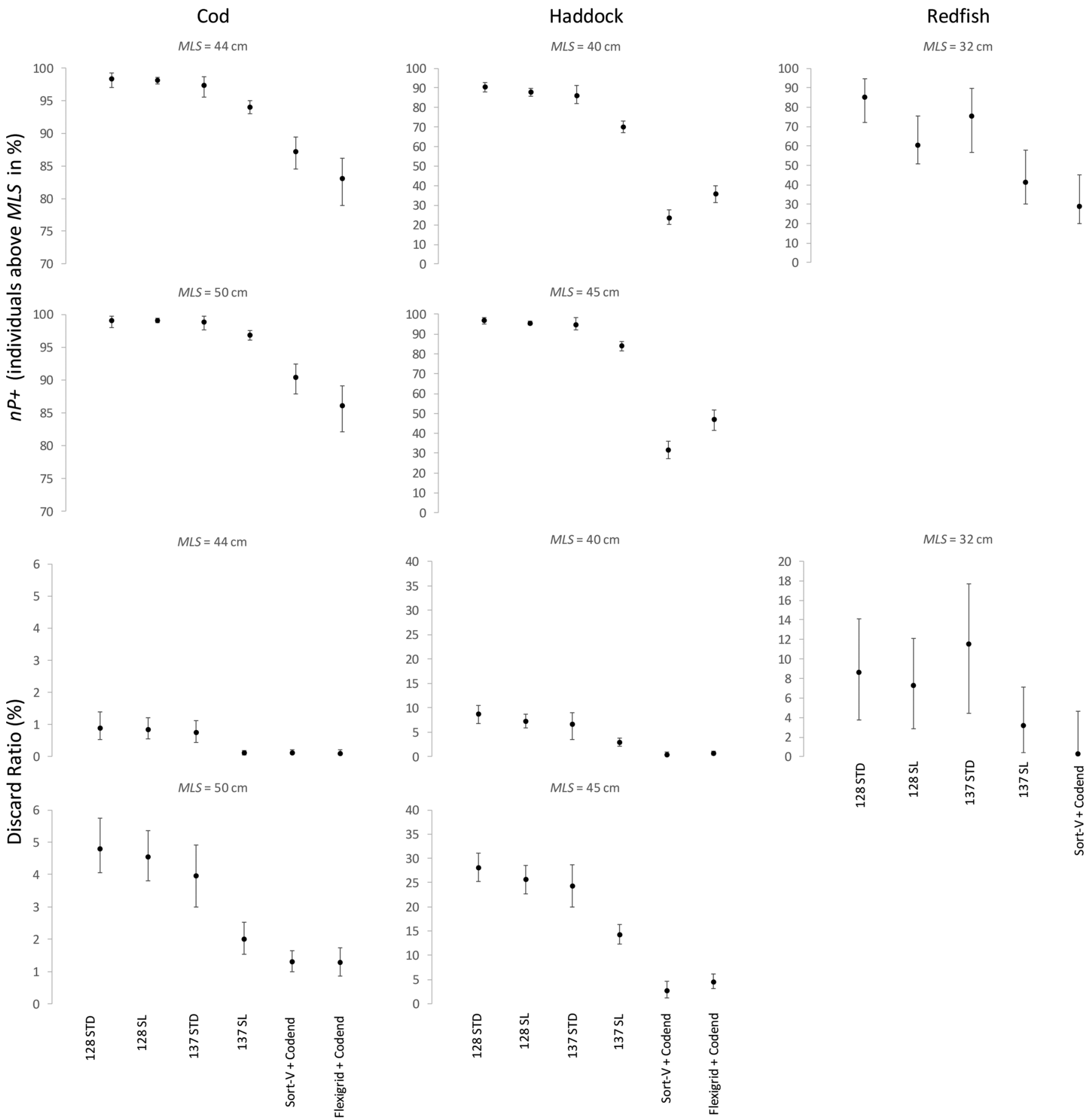

gear, species like cod are often more dependent on additional stimuli to attempt escape (Tschernij and Suuronen 2002; Grimaldo et al. 2018). Decompression experienced during haul back can be an additional escape stimulus (Madsen et al. 2008; Grimaldo et al. 2009, 2014), but it creates additional risk of injury and potentially reduced survival for the escapees (Breen et al. 2007). Earlier studies reported that contrary to the selectivity of codends, grid selectivity is a more mechanical size-selection process that takes place at the fishing depth (Grimaldo et al. 2009). This argument is often used by the management authorities in the Barents Sea to maintain the grid and codend configuration that is compulsory in the area today. Whether the properties of codends with shortened lastridge ropes are different from ordinary codends in this respect is unknown and should be investigated, as the availability of more open meshes in the codend may stimulate fish to escape earlier in the capture process. 
Netting meshes can change their physical properties over time, which can lead to that selectivity devices constructed of netting meshes lose their selection properties. Square-meshed panels (e.g., the BACOMA codend (Herrmann et al. 2015; Madsen et al. 2015), codends with lateral exit windows (Grimaldo et al. 2008, 2009), and T90 codends (ICES 2011; Madsen et al. 2015; Cheng et al. 2020)) have good selection properties for cod and haddock. However, deformation of the meshes and loss of stiffness over time may change the selection properties of these types of codends. Likewise, codends with lastridge ropes can potentially lose their properties over time. Ropes, especially twisted ropes, stretch with use, and this property depends on rope construction and material (McKenna et al. 2004). If ropes increase in length, the effect of shortened lastridge ropes would be reduced over time and the meshes in the codend would close. If ropes stretch, the crew may have to adjust them repeatedly to avoid losing the selective properties of the gear and comply with regulations. A potential solution to avoid stretching is the use of Dyneema ropes, which in principle stretch little $(<3.5 \%$; Thomas and Lekshmi 2017). However, Dyneema ropes have little load absorption due to their limited stretchability. Thus, material selection is a key to designing appropriate lastridge ropes, and further research of the quality and performance over time of different types of lastridge ropes is necessary.

Considering the results obtained in earlier trials (Isaksen and Valdemarsen 1990; Lök et al. 1997; Ingolfsson and Brinkhof 2020) and the results from our study, we conclude that codends with shortened lastridge ropes are satisfactory selection devices that could be used in the Barents Sea gadoid fishery and other fisheries to replace or supplement other sorting devices. However, selection during the capture process and the properties and performance of different types of lastridge ropes over time require further investigation.

\section{Acknowledgements}

We express our gratitude to the crew of the R/V Helmer Hanssen and to John Terje Eilertsen, Ivan Tatone, Clemens Knittel, Gaute Ringvall, Andreas Eilefsen, and Ronan Gombau for their help during the experimental trials at sea. We also thank the Norwegian Directorate of Fisheries and the Norwegian Fisheries and Aquaculture Research Fund (project number 901633) for funding the project.

\section{References}

Akaike, H. 1974. A new look at the statistical model identification. IEEE Trans. Autom. Control, 19: 716-723. doi:10.1109/TAC.1974.1100705.

Bergstad, O.A., Jørgensen, T., and Dragesund, O. 1987. Life history and ecology of the gadoid resources of the Barents Sea. Fish. Res. 5: 119-161. doi:10.1016/0165-7836(87)90037-3.

Breen, M., Huse, I., Ingolfsson, O.A., Madsen, N., and Soldal, A.V. 2007. Survival: An assessment of mortality in fish escaping from trawl codends and its use in fisheries management. EU Contract Q5RS-2002-01603 Final Report.

Brinkhof, J., Larsen, R.B., Herrmann, B., and Sistiaga, M. 2020. Size selectivity and catch efficiency of bottom trawl with a double sorting grid and diamond mesh codend in the North-east Atlantic gadoid fishery. Fish. Res. 231: 105647. doi:10.1016/j.fishres.2020.105647.

Cheng, Z., Einarsson, H.A., Bayse, S., Herrmann, B., and Winger, P. 2019. Comparing size selectivity of traditional and knotless diamond-mesh codends in the Iceland redfish (Sebastes spp.) fishery. Fish. Res. 216: 138-144. doi:10.1016/j. fishres.2019.04.009.

Cheng, Z., Winger, P.D., Bayse, S.M., Kebede, G.E., DeLouche, H., Einarsson, H.A., et al. 2020. Out with the old and in with the new: T90 codends improve size selectivity in the Canadian redfish (Sebastes mentella) trawl fishery. Can. J. Fish. Aquat. Sci. 77(10): 1711-1720. doi:10.1139/cjfas-2020-0063.

Cuende, E., Arregi, L., Herrmann, B., Sistiaga, M., and Aboitiz, X. 2020. Prediction of square mesh panel and codend size selectivity of blue whiting based on fish morphology. ICES J. Mar. Sci. 77: 2857-2869. doi:10.1093/icesjms/ fsaa156.

Efron, B. 1982. The jackknife, the bootstrap and other resampling plans. SIAM Monograph No. 38, CBSM-NSF. doi:10.1137/1.9781611970319.
Engås, A., and Godø, O.R. 1989. The effect of different sweep lengths on the length composition of bottom-sampling trawl catches. J. Cons. Int. Explor. 45: 263-268. doi:10.1093/icesjms/45.3.263.

Fryer, R.J. 1991. A model of between-haul variation in selectivity. ICES J. Mar. Sci. 48: 281-290. doi:10.1093/icesjms/48.3.281.

Graham, N., Kynoch, R., and Fryer, R. 2003. Square mesh panels in demersal trawls: further data relating haddock and whiting selectivity to panel position. Fish. Res. 62: 361-375. doi:10.1016/S0165-7836(02)00279-5.

Grimaldo, E., Larsen, R.B., and Holst, R. 2007. Exit windows as an alternative selective system for the Barents Sea demersal fishery for cod and haddock. Fish. Res. 85: 295-305. doi:10.1016/j.fishres.2007.03.005.

Grimaldo, E., Sistiaga, M., and Larsen, R.B. 2008. Evaluation of codends with sorting grids, exit windows, and diamond meshes: size selection and fish behaviour. Fish. Res. 91: 271-280. doi:10.1016/j.fishres.2007.12.003.

Grimaldo, E., Larsen, R.B., Sistiaga, M., Madsen, N., and Breen, M. 2009. Selectivity and escape percentages during three phases of the towing process for codends fitted with different selection systems. Fish. Res. 95 (2-3): 198-205. doi:10.1016/j.fishres.2008.08.019.

Grimaldo, E., Sistiaga, M., and Larsen, R.B. 2014. Development of catch control devices in the Barents Sea cod fishery. Fish. Res. 155: 122-126. doi:10.1016/j.fishres.2014.02.035.

Grimaldo, E., Sistiaga, M., Herrmann, B., and Larsen, R.B. 2016. Trawl selectivity in the Barents Sea demersal fishery. In Fisheries and aquaculture in the modern world. Edited by H. Mikkola. IntechOpen. doi:10.5772/63019.

Grimaldo, E., Sistiaga, M., Herrmann, B., Larsen, R.B., Brinkhof, J., and Tatone, I. 2018. Improving release efficiency of cod (Gadus morhua) and haddock (Melanogrammus aeglefinus) in the Barents Sea demersal trawl fishery by stimulating escape behaviour. Can. J. Fish. Aquat. Sci. 75(3): 402-416. doi:10.1139/cjfas-2017-0002.

Herrmann, B. 2005a. Effect of catch size and shape on the selectivity of diamond mesh cod-ends: I Model development. Fish. Res. 71: 1-13. doi:10.1016/j. fishres.2004.08.024.

Herrmann, B. 2005b. Effect of catch size and shape on the selectivity of diamond mesh cod-ends: II Theoretical study of haddock selection. Fish. Res. 71: 15-26. doi:10.1016/j.fishres.2004.08.021.

Herrmann, B., and O'Neill, F.G. 2005. Theoretical study of the between-haul variation of haddock selectivity in a diamond mesh cod-end. Fish. Res. 74: 243-252. doi:10.1016/j.fishres.2005.01.022.

Herrmann, B., Priour, D., and Krag, L.A. 2007. Simulation-based study of the combined effect on cod-end size selection for round fish of turning mesh 90 degrees and of reducing the number of meshes in the circumference. Fish. Res. 84: 222-232. doi:10.1016/j.fishres.2006.10.020.

Herrmann, B., Krag, L.A., Frandsen, R.P., Madsen, N., Lundgren, B., and Stæhr, K.J. 2009. Prediction of selectivity from morphological conditions: methodology and a case study on cod (Gadus morhua). Fish. Res. 97: 59-71. doi:10.1016/j. fishres.2009.01.002.

Herrmann, B., Sistiaga, M., Nielsen, K.N., and Larsen, R.B. 2012. Understanding the size selectivity of redfish (Sebastes spp.) in North Atlantic trawl codends. J. Northw. Atl. Fish. Sci. 44: 1-13. doi:10.2960/J.v44.m680.

Herrmann, B., Sistiaga, M., Larsen, R.B., Nielsen, K.N., and Grimaldo, E. 2013. Understanding sorting grid and codend size selectivity of Greenland halibut (Reinhardtius hippoglossoides). Fish. Res. 146: 59-73. doi:10.1016/j.fishres.2013.04.004.

Herrmann, B., Wienbeck, H., Karlsen, J.D., Stepputtis, D., Dahm, E., and Moderhak, W. 2015. Understanding the release efficiency of Atlantic cod (Gadus morhua) from trawls with a square mesh panel: effects of panel area, panel position, and stimulation of escape response. ICES J. Mar. Sci. 72: 686-696. doi:10.1093/icesjms/fsu124.

Herrmann, B., Krag, L.A., Feekings, J., and Noack, T. 2016. Understanding and predicting size selection in diamond mesh codends for Danish seining: a study based on sea trials and computer simulations. Mar. Coast. Fish. 8: 277-291. doi:10.1080/19425120.2016.1161682.

Herrmann, B., Krag, L.A., and Krafft, B.A. 2018. Size selection of Antarctic krill (Euphausia superba) in a commercial codend and trawl body. Fish. Res. 207: 49-54. doi:10.1016/j.fishres.2018.05.028.

ICES. 2011. Report of the Study Group on Turned $90^{3}$ Codend Selectivity, focusing on Baltic Cod Selectivity (SGTCOD), 4-6 May 2011, IMR, Reykjavik, Iceland. ICES. CM 2011/SSGESST:08.

ICES. 2012. Report of the ICES-FAO Working Group on Fishing Technology and Fish Behaviour (WGFTFB). ICES CM 2012/SSGESST:07.

Ingolfsson, O.A., and Brinkhof, J. 2020. Relative size selectivity of a fourpanel codend with short lastridge ropes compared to a flexigrid with a regular codend in the Barents Sea gadoid trawl fishery. Fish. Res. 232: 105724. doi:10.1016/j.fishres.2020.105724.

Isaksen, B., and Valdemarsen, J.W. 1986. Selectivity experiments with square mesh codends in bottom trawl. ICES C. M. 1986/B:28.

Isaksen, B., and Valdemarsen, J.W. 1990. Codend with short lastridge ropes to improve size selectivity in fish trawls. ICES CM 1990/. B46:8.

Jørgensen, T., Ingolfsson, I.A., Graham, N., and Isaksen, B. 2006. Size selection of cod by rigid grids - Is anything gained compared to diamond mesh codends only? Fish. Res. 79: 337-348. doi:10.1016/j.fishres.2006.01.017.

Kalogirou, S., Pihl, L., Maravelias, C.D., Herrmann, B., Smith, C.J., Papadopoulou, N., et al. 2019. Shrimp trap selectivity in a Mediterranean small-scale-fishery. Fish. Res. 211: 131-140. doi:10.1016/j.fishres.2018.11.006. 
Larsen, R.B., and Isaksen, B. 1993. Size selectivity of rigid sorting grids in bottom trawls for Atlantic cod (Gadus morhua) and haddock (Melanogrammus aeglefinus). ICES Mar. Sci. Symp. 196: 178-182.

Larsen, R.B., Herrmann, B., Sistiaga, M., Grimaldo, E., Tatone, I., and Onandia, I. 2016. Size selection of redfish (Sebastes spp.) in a double grid system: quantifying escapement through individual grids and comparison to former grid trials. Fish. Res. 183: 385-395. doi:10.1016/j.fishres.2016.07.013.

Larsen, R.B., Herrmann, B., Sistiaga, M., Brčić, J., Brinkhof, J., and Tatone, I. 2018. Could green artificial light reduce bycatch during Barents Sea deep-water shrimp trawling? Fish. Res. 204: 441-447. doi:10.1016/j.fishres.2018.03.023.

Lök, A., Tokaç, A., Tosunoğlu, Z., Metin, C., and Ferro, R.S.T. 1997. The effects of different codend design on bottom trawl selectivity in Turkish fisheries of the Aegean Sea. Fish. Res. 32: 149-156. doi:10.1016/S0165-7836(97) 00048-9.

Lomeli, M.J.M. 2019. Bycatch Reduction in Eastern North Pacific Trawl Fisheries. A dissertation for the degree of Doctor Philosophiae, The Arctic University of Norway, Faculty of Biosciences, Fisheries and Economy, Norwegian College of Fishery Science, Troms $\emptyset$, Norway.

Madsen, N., Skeide, R., Breen, M., Krag, L.A., Huse, I., and Soldal, A.V. 2008. Selectivity in trawl codend during haul-back operation - an overlooked phenomenon. Fish. Res. 91 (2-3): 168-174. doi:10.1016/j.fishres.2007.11.016.

Madsen, N., Hansen, K., and Madsen, N.A.H. 2015. Behavior of different trawl codends concepts. Ocean Eng. 108: 571-577. doi:10.1016/j.oceaneng.2015.08.047.

McKenna, H.A., Hearle, J.W.S., and O'Hear, N. 2004. Handbook of fibre rope technology. Woodhead Publishing, Cambridge, England.

Melli, V., Herrmann, B., Karlsen, J.D., Feekings, J.P., and Krag, L.A. 2020. Predicting optimal combinations of bycatch reduction devices in trawl gears: a meta-analytical approach. Fish Fish. 21(2): 252-268. doi:10.1111/ faf.12428.

Millar, R.B. 1993. Incorporation of between-haul variation using bootstrapping and nonparametric estimation of selection curves. Fish. Bull. 91: 564-572.

Norwegian Directorate of Fisheries. 2017. J-181-2017: Forskrift om bruk av sorteringsristsystem i fiske med stormasket trål. [In Norwegian.] Available from https://www.fiskeridir.no/Yrkesfiske/Regelverk-og-reguleringer/ J-meldinger/Gjeldende-J-meldinger/J-181-2017.

Olsen, E., Aanes, S., Mehl, S., Holst, J.C., Aglen, A., and Gjøsæter, H. 2010. Cod, haddock, saithe, and capelin in the Barents Sea and adjacent waters: a review of the biological value of the area. ICES J. Mar. Sci. 67: 87-101. doi:10.1093/icesjms/ fsp229.

O'Neill, F.G., and Herrmann, B. 2007. PRESEMO - a predictive model of codend selectivity - a tool for fisheries managers. ICES J. Mar. Sci. 64: 1558-1568. doi:10.1093/icesjms/fsm101.
Robertson, J.H.B., and Stewart, P.A.M. 1988. A comparison of size selection of haddock and whiting by square and diamond mesh codends. J. Cons. CIEM. 44: 148-161. doi:10.1093/icesjms/44.2.148.

Sala, A., and Lucchetti, A. 2011. Effect of mesh size and codend circumference on selectivity in the Mediterranean demersal trawl fisheries. Fish. Res. 110: 252-258. doi:10.1016/j.fishres.2011.04.012.

Sala, A., Lucchetti, A., Piccinetti, C., and Ferretti, M. 2008. Size selection by diamond and square-mesh codends in multi-species Mediterranean demersal trawl fisheries. Fish. Res. 93: 8-21. doi:10.1016/j.fishres.2008.02.003.

Sala, A., Brčić, J., Herrmann, B., Lucchetti, A., and Virgili, M. 2017. Assessment of size selectivity in hydraulic clam dredge fisheries. Can. J. Fish. Aquat. Sci. 74(3): 339-348. doi:10.1139/cjfas-2015-0199.

Santos, J., Herrmann, B., Mieske, B., Stepputtis, D., Krumme, U., and Nilsson, H. 2016. Reducing flatfish by-catches in roundfish fisheries. Fish. Res. 184: 64-73. doi:10.1016/j.fishres.2015.08.025.

Sistiaga, M., Grimaldo, E., and Larsen, R.B. 2008. Size selectivity patterns in the north-east Arctic cod and haddock fishery with sorting grids of 55, 60, 70 and 80mm. Fish. Res. 93: 195-203. doi:10.1016/j.fishres.2008.04.014.

Sistiaga, M., Herrmann, B., Grimaldo, E., and Larsen, R.B. 2010. Assessment of dual selection in grid based selectivity systems. Fish. Res. 105: 187-199. doi:10.1016/j. fishres.2010.05.006.

Sistiaga, M., Herrmann, B., Nielsen, K.N., and Larsen, R.B. 2011. Understanding limits to cod and haddock separation using size selectivity in a multispecies trawl fishery: an application of FISHSELECT. Can. J. Fish. Aquat. Sci. 68(5): 927-940. doi:10.1139/f2011-017.

Sistiaga, M., Brinkhof, J., Herrmann, B., Grimaldo, E., Langård, L., and Lilleng, D. 2016. Size selective performance of two flexible sorting grid designs in the Northeast Arctic cod (Gadus morhua) and haddock (Melanogrammus aeglefinus) fishery. Fish. Res. 183: 340-351. doi:10.1016/j.fishres.2016.06.022.

Thomas, S., and Lekshmi, M. 2017. Recent trends in fishing gear materials. In Recent trends in harvest and post-harvest technologies in fisheries. Edited by C.N. Ravishankar, M.M. Prasad, A.K. Mohanty, V. Murugadas, N. ManjuLekshmi, R. Anandan, et al. Central Institute of Fisheries Technology, Kochi, India.

Tschernij, V., and Suuronen, P. 2002. Improving trawl selectivity in the Baltic. Nordic Council of Ministers, Copenhagen, Denmark. TemaNord 2002. No. 512.

Wienbeck, H., Herrmann, B., Moderhak, W., and Stepputtis, D. 2011. Effect of netting direction and number of meshes around on size selection in the codend for Baltic cod (Gadus morhua). Fish. Res. 109: 80-88. doi:10.1016/j.fishres.2011.01.019.

Wileman, D., Ferro, R.S.T., Fonteyne, R., and Millar, R.B. (Editors). 1996. Manual of methods of measuring the selectivity of towed fishing gears. ICES Cooperative Research report No. 215. doi:10.17895/ices.pub.4628. 